\section{Tier-based approaches for landslide \\ 2 susceptibility assessment in Europe}

3 Andreas Günther ${ }^{1, *}$, Paola Reichenbach ${ }^{2}$, Jean-Philippe Malet ${ }^{3}$, Miet Van Den

4 Eeckhaut $^{4}$, Javier Hervás ${ }^{4}$, Claire Foster ${ }^{5}$, Fausto Guzzetti ${ }^{2}$

$5{ }^{1}$ Federal Institute for Geosciences and Natural Resources, Hannover, Germany

$6 \quad{ }^{2}$ Consiglio Nazionale delle Ricerche, Istituto di Ricerca per la Protezione

7 Idrogeologica, Perugia, Italy

$8{ }^{3}$ Institut de Physique du Globe de Strasbourg (CNRS UMR 7516), Université de

$9 \quad$ Strasbourg / EOST, Strasbourg France

$10{ }^{4}$ Institute for Environment and Sustainability, Joint Research Centre, European

11 Commission, Ispra (VA), Italy

$12{ }^{5}$ British Geological Survey, Nottingham, United Kingdom

13

$14 *$ Correspondence:

15 Andreas Günther

16 Federal Institute for Geosciences and Natural Resources

17 Stilleweg 2, D-30655 Hannover, Germany

18 Phone: $+49+5116432448$

19 Email: a.guenther@bgr.de

20

21

22

23

24

25

26

27

28

29

30

31

32 


\section{Abstract}

2 In the framework of the European Soil Thematic Strategy and the associated proposal of a

3 Framework Directive on the protection and sustainable use of soil, landslides were recognised as a

4 soil threat requiring specific strategies for priority area identification, spatial hazard assessment

5 and management. This contribution outlines the general specifications for nested, Tier-based

6 geographical landslide zonings at small spatial scales to identify priority areas susceptible to

7 landslides (Tier 1), and to perform quantitative susceptibility evaluations within these (Tier 2). A

8 heuristic, synoptic-scale Tier 1 assessment exploiting a reduced set of geo-environmental factors

9 derived from common pan-European data sources is proposed for the European Union and

10 adjacent countries. Evaluation of the susceptibility estimate with national-level landslide inventory

11 data suggests that a zonation of Europe according to e.g. morphology and climate, and performing

12 separate susceptibility assessments per zone could give more reliable results. To improve the Tier

131 assessment, a geomorphological terrain zoning and landslide typology differentiation are then

14 applied for France. A multivariate landslide susceptibility assessment using additional information

15 on landslide conditioning and triggering factors, together with a historical catalogue of landslides,

16 is proposed for Tier 2 analysis. An approach is tested for priority areas in Italy using small

17 administrative mapping units, allowing for relating socio-economic census data with landslide

18 susceptibility, which is mandatory for decision making regarding the adoption of landslide

19 prevention and mitigation measures. The paper concludes with recommendations on further work

20 to harmonise European landslide susceptibility assessments in the context of the European Soil

21 Thematic Strategy.

23 Keywords: Small-scale landslide zoning, Heuristic Tier 1 assessment, Statistical

24 Tier 2 assessment, European Soil Thematic Strategy, Common landslide

25 susceptibility criteria, Europe. 


\section{Introduction}

2 Landslide susceptibility is the likelihood of a landslide occurring in an area

3 controlled by local terrain conditions (e.g., Brabb 1984; Guzzetti et al. 1999; Fell

4 et al. 2008). It is the degree to which a terrain can be affected by future slope

5 movements. Susceptibility does not consider the temporal probability of failure

6 (i.e., when or how frequently landslides occur), or the magnitude of the expected

7 events (i.e., how large or destructive possible failures may be) (Committee on the

8 Review of the National Landslide Hazards Mitigation Strategy 2004). With this

9 respect, landslide susceptibility evaluations resembling basic spatial landslide

10 zoning differ from landslide hazard (e.g., Guzzetti et al. 1999; van Westen et al.

11 2005), and landslide risk assessments (e.g., Glade et al. 2005; Fell et al. 2008).

12 The relevance of landslide zoning for environmental policy and decision

13 making in Europe is set forth in the framework of the European Union's Thematic

14 Strategy for Soil Protection, adopted on 22 September 2006 (EC 2006a). This

15 Strategy considers landslides as one of eight soil threats in Europe for which it is

16 necessary to identify areas where landslides are likely to occur in the future, and

17 where measures to reduce the impact of the threat have to be designed. To achieve

18 these objectives, a Soil Framework Directive was proposed as a legislative

19 initiative (EC 2006b, EC 2012). The importance of landslide zoning through

20 spatial susceptibility assessments in Europe is additionally recognised in the

21 European Commission's approach to natural and man-made disaster prevention

22 (EC 2009). Furthermore, the production of comparable maps for European Union

23 member countries showing the expected spatial distribution of major threats

24 including landslides has been recommended by the European Commission as a

25 first step towards producing national-level risk maps for disaster emergency

26 management using coherent and consistent risk assessment methodologies (EC 27 2010).

28 To identify areas of interest for landslide zonation, the Soil Information

29 Thematic Working Group (SIWG) of the European Soil Bureau Network (ESBN)

30 selected i) a set of common criteria (i.e., environmental and thematic factor data

31 to predict landslide susceptibility), including landslide occurrence or density,

32 topography, bedrock, soil type, land cover, land use, climate and seismicity

33 (Eckelmann et al. 2006), and ii) a nested assessment approach based on "Tiers".

34 In this context, a Tier 1 assessment is aimed at the general identification of 
1 priority areas threatened by landslides using common criteria derived from

2 available spatial datasets through a qualitative evaluation procedure combined

3 with thresholds. The Tier 2 assessment is intended to perform quantitative

4 landslide susceptibility analyses in priority areas identified by Tier 1 incorporating

5 additional (including not yet existent) data. This framework should allow the EU

6 member countries to delineate priority areas through a Tier 1 assessment

7 exploiting either pan-European, low-resolution data or spatial information with

8 higher resolution available at national or regional levels. For the identification of

9 priority areas through Tier 1, these have to be combined with a suitable threshold

10 to discriminate priority areas against terrains where no further action has to be 11 taken.

12 Since the two Tiers can be conducted at various spatial scales depending 13 on input data resolution and spatial extent, Tier 2 should not be considered an 14 alternative for priority area delineation through Tier 1 but rather should provide 15 more accurate spatial information for the establishment of targets and programmes 16 of measures to combat soil threats in the EU member states (EC 2006b). The 17 proposal for the soil framework directive attempts to provide a general framework 18 to enable the member countries to identify priority areas, decide on appropriate 19 general measures and targets to fight soil degradation within these, and enable a 20 reporting policy on this (EC 2006b). In terms of landslides, the Tier-based 21 concept for susceptibility evaluation must therefore be regarded to support general 22 EU policy implementation but not as a regulation for measures to mitigate and 23 monitor individual landslides and their consequences.

24 The initial work of the SIWG was put forward by the European Landslide 25 Expert Group (http://eusoils.jrc.ec.europa.eu/library/themes/Landslides) established in 2007 26 at JRC Ispra (Hervás et al. 2007). It was recognized that since a comprehensive, 27 distributed landslide inventory does not exist over Europe and many European 28 regions lack information on landslides (Van Den Eeckhaut and Hervás 2012), 29 index-based heuristic susceptibility evaluations calibrated and validated with 30 regional level landslide data should be envisaged for continental-level Tier 1 31 assessments (Hervás et al. 2007, Günther et al. 2008). It was further specified that 32 Tier 1 should be performed using reduced spatial information on solely three 33 environmental factors supposed to have a major control on all types of landslides 34 (e.g., van Westen et al. 2009): terrain gradient, lithology and land cover. 
1 Important variables merely related to landslide triggering like spatial information

2 on groundwater and soil moisture conditions, precipitation or seismicity were

3 excluded at this stage, because they reveal a high degree of temporal variability

4 and are more suitable for hazard analysis. As a mapping unit, a grid cell with a

5 size depending on input data resolution and analysis extent was recommended. A

6 continental-level Tier 1 assessment should be prepared employing a $1 \mathrm{~km} \mathrm{x} 1 \mathrm{~km}$

7 grid cell (Hervás et al. 2007). Tier 2 evaluations should be carried out through

8 inventory-based, statistical analyses utilizing a wider range of environmental and

9 triggering factor data. To allow for decision on measures/implementation plans

10 for the landslide threat, it was recommended to use terrain units of appropriate

11 size for the analysis. These may consist of administrative, agroeconomic or

12 geomorphometric entities allowing for a direct association of landslide

13 susceptibility with economic or population-based census data.

14 In this work, we first present and evaluate the results of an experiment 15 carried out in the framework of the European Landslide Expert Group, aimed at 16 producing a preliminary synoptic-scale, index-based, landslide susceptibility 17 assessment for Europe, reflecting a basic continental Tier 1 susceptibility 18 evaluation. Next, we present and discuss two national-scale landslide 19 susceptibility assessments and their associated terrain zonations for France and 20 Italy. The example for France resembles a more advanced Tier 1 assessment since 21 it uses the same type of reduced geo-environmental data and does not necessarily 22 require information on landslide distribution, but introduces a differentiation 23 according to terrain physiography and landside typology. The example for Italy 24 represents a small-scale Tier 2 quantitative susceptibility analysis within priority 25 areas as defined by the continental-level Tier 1 assessment. This analysis is based 26 on distributed landslide information and additional thematic data. We conclude 27 discussing problems and advantages of the presented small-scale landslide 28 susceptibility analyses, and pointing out future work to be done to improve both 29 Tier 1 and Tier 2-compatible attempts for harmonised landslide zoning in the 30 context of the European Soil Thematic Strategy. 


\section{Europe}

3 We prepared a synoptic-scale landslide susceptibility model and an associated

4 susceptibility map for Europe at 1:1M scale to identify priority areas for landslide

5 zoning. The map covers the 27 EU member countries (except Cyprus) in addition

6 to Norway, Switzerland and the Balkan states (Fig. 1). As mapping unit, a grid

7 cell size of $1 \mathrm{~km}$ x $1 \mathrm{~km}$ was selected (Hervás et al. 2007). In this section, we first

8 describe the data and the data evaluation approach adopted to prepare the zonation

9 of landslide susceptibility in Europe. Then we discuss the validation of the

10 synoptic landslide susceptibility zonation in France, Great Britain and Italy, three

11 European countries for which comprehensive landslide information was available

12 to us. Last, we compare the continental landslide susceptibility map with other

13 global (Nadim et al. 2006; Hong et al. 2007) and continental (Schmidt-Thomé

14 2006) landslide susceptibility and hazard evaluations that may also be considered

15 for continental scale Tier 1 assessments.

\section{Data}

18 To model landslide susceptibility in Europe, we used small-scale geo19 environmental information available in digital format from public sources, 20 including information on terrain gradient (slope), lithology, and land cover (Table

21 1). Information on terrain gradient was obtained from the GTOPO30 global 22 elevation model

23 (http://eros.usgs.gov/\#/Find_Data/Products_and_Data_Available/gtopo30_info). This global

24 digital coverage of topography has a horizontal grid spacing of 30 arc seconds 25 (approximately $1 \mathrm{~km}$ ), and was completed in 1996 by the USGS EROS Data 26 Center. Terrain slope was computed from the elevation data in a Geographical 27 Information System (GIS). We acknowledge that the computed slope values, in 28 the range $0-38.9^{\circ}$ (average $=2.3^{\circ}$, standard deviation $\left.=3.4^{\circ}\right)$, do not represent 29 the actual terrain gradient at any specific point, and we consider the computed 30 slope a proxy for the general topographic gradient in the study area.

Spatial information on lithology was obtained exploiting the European Soil

32 Database (ESDB) (Heineke et al. 1998; Panagos et al. 2012; 33 http://eusoils.jrc.ec.europa.eu/ESDB_Archive/ESDB/index.htm). The geometry of the ESDB 
1 is provided by soil mapping units (SMU), which can be related to more than 20

2 attributes of so-called Soil Typological Units (STU) describing several properties

3 of dominant and co-dominant soils. To obtain the lithological information

4 required for the analysis, the attribute "dominant parent material" at level 2

5 (MAT12), subdivided in 41 classes of soil parent material, was selected. The

6 SMU polygons attributed to MAT12 have been rasterized at a $1 \mathrm{~km} \times 1 \mathrm{~km}$ grid

7 resolution. The soil parent material information attributed in the ESDB comprises

8 first-order genetic and petrologic information on geological materials on which

9 soils evolve, derived from different European geological map datasets (Finke et

10 al. 2001). We have chosen the dominant parent material data from the ESDB

11 against alternative digital data (e.g., solid bedrock geology from the International

12 Geological Map of Europe; Asch 2005) as a proxy for near-surface lithology

13 because of its higher resolution and because it also renders spatial information on

14 the distribution of quaternary and unconsolidated geological materials.

We obtained spatial information on land cover from the Pan-European

16 Land Cover Monitoring Project (PELCOM) which produced a gridded, $1 \mathrm{~km} \times 1$

$17 \mathrm{~km}$ resolution land cover database for the period 1996-1999 (http://www.geo-

18 informatie.nl/projects/pelcom/). The land cover information, in 14 classes, was

19 obtained from multi-temporal and multi-spectral NOAA-AVHRR satellite

20 imagery and other ancillary data (namely CORINE and Digital Chart of the

21 World). For the purpose of this study, terrains covered by the three classes ice and

22 snow, sea, and inland waters were excluded from the analysis, and eleven classes

23 of land cover were considered.

24 For the synoptic-scale analysis of landslide susceptibility in Europe, we re25 classified the terrain gradient, lithological, and land cover information in a 26 reduced number of classes, including: (i) five classes of terrain slope, (ii) five 27 lithological classes representing major lithological complexes as derived from the 28 soil parent material information, and (iii) five land cover classes (Fig. 2). The 29 reclassification of the input data was based on our understanding of the landslide 30 phenomena in Europe, and on the known or expected relevance of the three 31 considered environmental factors in controlling the susceptibility to landslides.

32 However, it should be mentioned that the proposed parameter classification tries

33 to globally specify the input data for all types of landslides and has clear 34 limitations with respect to regionally differentiated interpretations (see further). 
In addition to the mentioned environmental data, we used national-scale

2 landslide information for France, Great Britain, and Italy (Fig. 3) to evaluate the

3 preliminary European susceptibility zonation. The three countries cover $22 \%$ of

4 the study area. For France, we used the national landslide database BDMvT (a

5 French acronym for Base de Données Nationale Mouvements de Terrain,

6 http://www.bdmvt.net/) (Fig. 3A). The inventory is the result of a joint effort of the

7 Bureau de Recherches Géologiques et Minières, the Laboratoire des Ponts et

8 Chaussées, and the Restauration des Terrain en Montagne. The database contains

9 information on 17,598 landslides (June 2010), including movement type (Varnes

10 1978), geographical location, date and time of occurrence, state of activity, and

11 damage caused by the collected landslides. For Great Britain, we used the

12 National Landslide Database produced and maintained by the British Geological

13 Survey, which lists detailed information on 15,897 landslides (October 2011).

14 Compilation of the database started in the late 1980's through a combination of

15 existing data sources. Since then, information on more than 6,000 additional

16 landslides was added to the database (Foster et al. 2008; Evans et al. 2011) (Fig.

17 3B). For Italy, we used the catalogue of historical landslides compiled by the AVI

18 project (an Italian acronym for Aree Vulnerate Italiane, Areas Affected by

19 Landslides and Floods in Italy, http://sici.irpi.cnr.it/) through a methodical search

20 of national, regional, and local chronicles and historical archives (Guzzetti et al.

21 1994; Guzzetti and Tonelli 2004). Landslides listed in the catalogue were mapped

22 as points at 1:25,000 or 1:100,000 scale, and a level of geographic accuracy, in

23 five classes, was attributed to each mapped landslide. The original AVI catalogue

24 covers the period from pre-1900 to 2002. To minimize the effects of 25 incompleteness in the early period of the catalogue, for the assessment of 26 landslide susceptibility we selected 15,503 landslides in the 52-year period 1950-

272001 (Fig. 3C). We chose this historical dataset against a more recent and more 28 exhaustive national-level landslide inventory prepared by the IFFI project 29 (http://www.isprambiente.gov.it/site/en-GB/Projects/IFFI_Project/default.html,

30 Trigilia et al. 2010) because this data was not completely available for this study.

31 Moreover, we preferred to use the historical catalogue for Italy to allow for

32 temporal validation of a statistical Tier 2 example discussed below. 
1 Methodology

2 We adopted a heuristic approach, quantified through an Analytic Hierarchy

3 Process (AHP) technique for susceptibility evaluation. This is an expert-based,

4 stepwise classification technique designed to hierarchically organize criteria (here:

5 environmental variables influencing landslide susceptibility) to solve complex

6 decisions through pairwise comparisons of their relative importance on a scale

7 from 1 - 9 (Saaty 1980). AHP has been applied for heuristic landslide

8 susceptibility zoning lacking extensive inventory information (e.g., Barredo et al.

9 2000; Gorsevski et al. 2006; Yalcin 2008; Castellanos Albella and van Westen 10 2008).

11 For organizing the three equally classified spatial criteria for landslide 12 susceptibility used in this study, first the relative weights for the five individual 13 classes of each criterion (i.e., slope gradient, lithology, and land cover) were 14 directly assigned based on our understanding of landslide susceptibility over 15 Europe as predicted by the data used in this study. Steeper terrain was attributed a 16 higher susceptibility than gentle terrain. Soft materials (e.g., predominantly clayey 17 and unconsolidated lithologies) known to be prone to failure were assigned a high 18 weight, and strong lithologies (e.g., metamorphic and highly consolidated rocks) 19 were attributed a low weight. Forests and grasslands were considered more prone 20 to landslides than croplands and wetlands. For convenience, all factor weights 21 were normalized (Table 2).

22 Next, the relative importance of the three used criteria in conditioning 23 slope instability in Europe was decided. For this instance, pairwise comparisons 24 of the three factors were performed within the AHP giving slope a moderately 25 higher importance than lithology, slope a strongly higher importance than land 26 cover, and lithology a moderately higher importance than land cover. This 27 operation results in normalized weight values of 0.64 for slope, 0.26 for lithology, 28 and 0.10 for land cover (Table 2), with an consistency ratio of 0.03 indicating a 29 valid pairwise comparison matrix (Saaty and Vargas, 1984). We acknowledge that 30 the relative importance of the single criteria may not work everywhere in the 31 study area, and the corresponding weights assigned to the criteria may result in 32 local inconsistencies. However, we maintain that the assigned normalized relative 33 weights are reasonable for most of Europe. 
The integration of the weighted parameter classes into a landslide

$$
S=\sum_{j=1}^{n=3} w_{j} \cdot x_{i j}
$$

5 where $w_{j}$ is the weight of criterion $j$ and $x_{i j}$ is the weight of class $i$ for criterion $j$.

6 Finally, the continuous susceptibility index resulting from the weighted linear

7 summation of the criteria classes with Eq. 1 was classified into five levels

8 through equal-interval slicing, used to prepare the synoptic-scale landslide

9 susceptibility zonation of Europe shown in Fig. 4A. In Fig. 4B, total area and

10 landslide proportions of the five susceptibility categories are shown, together with

11 the frequency distribution of the continuous landslide susceptibility index S. From

12 this is can be inferred that $41.1 \%$ of the landslide locations in Britain, France and

13 Italy are within the two highest susceptibility classes covering an area of $16.6 \%$,

14 and only $7.9 \%$ of landslides are present in the majority of the study area attributed

15 to the lowest susceptibility class (39.3\%). We therefore suggest the applied

16 classification of $S$ resulting from trivial equal-interval slicing capable to produce a

17 reasonable synoptic landslide susceptibility zonation.

\section{Landslide susceptibility map}

20 The resulting synoptic-scale landslide susceptibility map for Europe (Fig. 4A) can

21 be evaluated qualitatively and quantitatively. For a qualitative evaluation, a visual 22 inspection of Fig. 4A reveals that areas where susceptibility to landslides is high 23 or very high concentrate in the main European mountain chains, including the 24 Alps, the Apennines, the Pyrenees, the Dinarides and the Carpathians. 25 Susceptibility is also high or very high in the mountains and hills of Greece and 26 Crete, in southern Spain, in southern Norway, and in western Scotland. Further 27 inspection of Fig. 4A shows that areas where susceptibility to landslides is low or 28 very low concentrate in Central and Northern Europe, include large portions of 29 the Iberian Peninsula, and ample parts of the Eastern European lowland. 30 Comparison of the susceptibility map (Fig. 4A) with the terrain gradient map (Fig. $312 \mathrm{~A}$ ) reveals that more than $50 \%$ of the highly susceptible terrain (3.0\% of Europe) 32 exhibits terrain gradients exceeding $15^{\circ}$ and more than $95 \%$ of the area classified 
as having a very low landslide susceptibility (39.3\% of Europe) has a terrain

2 gradient lower than $1^{\circ}$. Visual inspection of Fig. 4A also reveals areas where the

3 continental-scale susceptibility assessment underestimates the propensity of the

4 terrain to generate landslides. This is particularly evident in generally low-relief

5 areas of northern Europe (e.g., southern England, northern France) and Central

6 European highlands known to be landslide-prone. Additionally, many coastal

7 areas in e.g. England, France and Italy are underrepresented in terms of landslide

8 susceptibility. These circumstances result from the global susceptibility evaluation

9 that does not incorporate physiography-specific class weights of the geo-

10 environmental data used.

11 A quantitative evaluation of the performance of the synoptic landslide 12 susceptibility zonation of Europe can be performed exploiting the landslide 13 information available for France, Great Britain and Italy (Fig. 3). For the purpose, 14 we prepared Receiver Operating Characteristics (ROC) curves (Metz 1978; 15 Mason and Graham 2002; Fawcett 2006) using the three individual national 16 landslide datasets and the ensemble of the three datasets (Fig. 4C). Adopting the 17 Area Under the ROC Curve (AUC) metric as a quantitative measure of the ability 18 of the susceptibility model to predict the landslide locations, we notice that the 19 synoptic-scale susceptibility zonation performed best in France (AUC $=0.75$ ), 20 followed by Great Britain $($ AUC $=0.64)$ and Italy $($ AUC $=0.61)$. Considering the 21 ensemble of the landslide information in the three countries, the metric was AUC $22=0.72$. It has to be emphasized that the ROC evaluation can only be considered as 23 an indication of model performance in areas where distributed landslide 24 information is available, and cannot be used as a quality criterion for the overall susceptibility map.

26 An additional quantitative evaluation of the susceptibility model consists 27 in comparing the performance of the susceptibility zonation with the performance 28 of a classification based solely on slope gradient (Remondo et al. 2003). Dashed 29 lines in Fig. 4C show ROC curves obtained comparing the spatial distribution of 30 landslides with the distribution of terrain gradient in France, Great Britain, and 31 Italy. The AUC metrics for the three individual countries (France AUC $=0.73$, 32 Great Britain AUC $=0.60$, Italy AUC $=0.60)$, and for the combined landslide 33 dataset $(\mathrm{AUC}=0.67)$, show that the performance of the AHP-based multi-criteria 34 classification model was consistently higher than the performance of the 
1 corresponding classifications obtained using solely the terrain slope. The

2 differences in the AUC values measure the improvement in the terrain

3 classification resulting from the use of the lithology and the land cover

4 information, in addition to the slope information. We acknowledge that the size of

5 the improvement is partly dependent on the relative weights attributed

6 heuristically to the three susceptibility criteria (i.e., 0.64 for terrain gradient, 0.26

7 for lithology, and 0.10 for land cover).

8 To use our continental-level evaluation for the delineation of priority areas

9 against terrains where no further action is necessary, a suitable susceptibility

10 index threshold value has to be established. Based on our synoptic scale analysis,

11 we conservatively consider areas classified as very high, high and moderate

12 susceptibility as priority areas subjected to quantitative, inventory-based landslide

13 susceptibility evaluations (Tier 2). Application of this threshold classifies 36\% of

14 the analysed area as subjected to Tier 2 (Fig. 4). Because it is not known to what

15 extent landslides can be expected in specific areas classified as moderately 16 susceptible, we used a precautionary principle to identify priority areas over 17 Europe.

19 Comparison with continental and global landslide susceptibility models

20 The ability of our synoptic-scale landslide susceptibility assessment for Europe 21 (Fig. 4A) to predict the landslide locations in Great Britain, France and Italy 22 collected for this study can be compared to that of existing continental (Schmidt23 Thomé 2006) and global (Nadim et al. 2006; Hong et al. 2007) assessments of 24 landslide susceptibility and hazard (Fig. 5). In the context of the European Spatial 25 Planning Observation Network (ESPON) Programme, Schmidt-Thomé (2006) 26 published a map showing the distribution of landslide "hazard" in Europe (Fig. 27 5A). The map adopted the NUTS (Nomenclature des Unités Territoriales 28 Statistiques) level 3 administrative units, and showed the propensity to landslides 29 for these mapping units in two classes: "low hazard" and "high hazard". Although 30 solely based on the opinion of experts of European geological surveys and 31 suffering from data gaps, the resulting continental map was the first to recognize 32 the importance and extent of landslide problems in Europe. A comparison of the 33 new synoptic-scale landslide susceptibility zonation (Fig. 4A) with the ESPON 34 "hazard" map of Europe (Fig. 5A) indicates that the ESPON zonation predicted 
1 correctly nearly $80 \%$ of the locations of the known landslides in France (Fig. 3A),

2 Great Britain (Fig. 3B) and Italy (Fig. 3C). However, the number and areal extent

3 of the NUTS 3 units predicted as landslide prone by the ESPON model and for

4 which no information is available in the three national inventories (i.e., false

5 positives) is large, reducing the credibility of the map. We attribute this

6 overestimation of landslide susceptibility to the large average size of the mapping

7 units, and we conclude that a NUTS level 3 mapping unit is inadequate (too large)

8 for the accurate definition of landslide susceptibility in Europe.

Hong et al. (2007) produced a global landslide susceptibility assessment

10 exploiting geo-environmental information obtained from a variety of geospatial

11 data sources, including (i) the GTOPO30 elevation dataset, (ii) land cover

12 information obtained by processing data captured by the Moderate Resolution

13 Imaging Spectroradiometer (MODIS) sensor aboard the NASA Terra and Aqua

14 satellites, and (iii) soil information extracted from the 2003 edition of the Digital

15 Soil of the World (FAO, http://www.fao.org) and from a soil database of the

16 International Satellite Land Surface Climatology Project Initiative (ISLSCP,

17 http://www.gewex.org/islscp.html). The coarse resolution geo-environmental

18 information was combined using a weighted linear combination method proposed

19 by Ayalew et al. (2004), with the weights attributed to the different landslide-

20 controlling factors decided heuristically. The result consisted in a low-resolution

21 (15 arc minutes, approx. $28 \mathrm{~km}$ ) global map showing landslide susceptibility in

22 five classes, from very low to very high susceptibility. Kirschbaum et al. (2009)

23 used this global landslide susceptibility zonation combined with satellite-derived

24 rainfall estimates to provide dynamic forecasts of landslide hazard in near real

25 time. Visual comparison of the European portion of the global landslide

26 susceptibility zonation of Hong et al. (2007) (Fig. 5B) with the new synoptic-scale

27 landslide susceptibility assessment for Europe made for this study (Fig. 4A)

28 indicates that, apart from their incompatible resolution, the resulting maps show a

29 certain degree of coincidence. However, in contrast to the susceptibility estimate

30 presented here, the map from Hong et al. (2007) is more pessimistic in Southern

31 Europe (e.g., the Iberian Peninsula and the East European basins).

32 Nadim et al. (2006) were first to produce a global map showing landslide

33 (and snow avalanche) hazard areas and risk hotspots. Their pioneering worldwide

34 hazard assessment was prepared through a linear combination of conditioning and 
1 triggering factors modulated by weights decided on expert opinion (e.g., Mora and

2 Vahrson 1994). The factors considered in the analysis included (i) terrain slope

3 computed from the GTOPO30 elevation dataset, (ii) lithology obtained

4 simplifying the 1:25M scale Geological Map of the World (CGMW 2000), and

5 (iii) soil moisture characteristics extracted from a moisture index global archive

6 for the period 1962-1990 (Willmot and Feddema 1992). The triggering factors

7 included (i) estimates for the 100-year extreme monthly rainfall obtained from the

8 Global Precipitation Climatology Centre managed by the German National

9 Meteorological Service (Rudolf et al. 2005), and (ii) the expected Peak Ground

10 Acceleration with a return period of 475 years, obtained from the Global Seismic

11 Hazard Programme (http://www.seismo.ethz.ch/static/GSHAP/). The resulting global

12 map with a resolution of 30 arc seconds (approx. $1 \mathrm{~km} \mathrm{x} 1 \mathrm{~km}$ ) was classified into

13 nine hazard classes, where only the values from six through nine are 14 downloadable as a raster dataset from

15 http://www.ldeo.columbia.edu/chrr/research/hotspots/coredata.html. Visual comparison of 16 our landslide susceptibility zonation for Europe (Fig. 4A) with the section for 17 Europe of the four highest hazard classes of the global map of Nadim et al. (2006)

18 (Fig. 5C) indicates that the latter exclusively delineates areas in high mountainous

19 regions having moderately to high landslide hazard and renders no information for 20 more than $90 \%$ of the area, including many European countries also facing 21 landslide problems (e.g., Great Britain, Germany, Belgium).

We evaluated the capability of the continental (Schmidt-Thomé

23 2006) and the global (Nadim et al. 2006; Hong et al. 2007) assessments of 24 landslide susceptibility and hazard to predict the landslide locations in Great 25 Britain, France and Italy in comparison to the new synoptic-scale susceptibility 26 assessment for Europe (Fig. 4). For this purpose, we compared the extent of the 27 various susceptibility classes with the location of slope failures in the ensemble of 28 the three historical landslide inventories available for France (Fig. 3A), Great 29 Britain (Fig. 3B) and Italy (Fig. 3C). This was used to construct the ROC curves 30 shown in Fig. 5D. Inspection of the ROC curves shows that the performance of 31 the susceptibility classification in France, Great Britain and Italy (AUC $=0.72$ ) 32 was larger than the performance of the global classification of Hong et al. (2007) 33 (AUC $=0.68)$ for the same three countries. Further analysis of the ROC curves 34 reveals that the global hazard classification of Nadim et al. (2006) exhibited a “j”- 
1 shaped ROC curve with AUC $=0.45$, mostly attributed to the fact that the map

2 only covers $3 \%$ of the area with more than $70 \%$ of the landslides outside the 3 hazard classes.

The continental and global landslide susceptibility and hazard zonations

In accordance to the general specifications for heuristic Tier 1 landslide susceptibility modelling proposed by Hervás et al. (2007), the national assessment

32 for France is based on the same reduced common criteria (e.g., spatial information 
1 but the input data sets differ in terms of resolution and taxonomy. Additionally

2 and most importantly, the susceptibility evaluation employs a differentiation

3 according to landslide typology (flows, slides and falls), and terrain physiography

4 (coasts, mountains and plains).

\section{Data}

7 Information on slope gradient was derived from the French elevation database 8 (BD-Alti®), at $50 \mathrm{~m} \times 50 \mathrm{~m}$ ground resolution. For susceptibility modelling,

9 terrain slope was computed and reclassified in 13 equally spaced classes $\left(5^{\circ}\right.$ 10 interval), from $0^{\circ}$ to $>60^{\circ}$. Information on soil parent material was obtained from 11 the $1: 1 \mathrm{M}$ scale digital Geological Map of France, and the associated digital 12 database prepared by BRGM (2005). Since the original lithological information 13 was too complex (and too detailed) for the purpose of the study, the data was 14 grouped in 24 lithological classes based on information on lithology, structure, 15 and age of the rocks. Also, the lithological information originally available in 16 vector format was transformed to a $50 \mathrm{~m} \times 50 \mathrm{~m}$ resolution grid spatially coherent 17 with the terrain gradient data. Information on land cover was obtained from the 18 CORINE Land Cover 2000 and 2006 databases (CLC2000, CLC2006) available 19 at 1:100,000 scale. For France, the databases show land cover characteristics in 20 ten classes, for terrain units larger than $0.25 \mathrm{~km}^{2}$. Information on landslides for 21 model calibration was obtained from the French national BDMvT inventory (Fig. 22 2A). This is the same inventory used for the evaluation of the synoptic-scale 23 landslide susceptibility assessment for Europe. All the slope failures listed in the 24 BDMvT inventory were classified as falls, flows, or slides, depending on their 25 primary type of movement (Varnes 1978).

\section{Methodology}

28 To evaluate landslide susceptibility in France, a Spatial Multi-Criteria Evaluation 29 (SMCE) technique (Figueira et al. 2005) as implemented in the ILWIS ${ }^{\circledR}$ software 30 was adopted (Castellanos Abella and van Westen 2008; Malet et al. 2009). The 31 technique is conceptually and operationally based on an AHP to decide on criteria 32 and criteria class weights as also used to determine landslide susceptibility over 33 Europe in this paper. Specifically, SMCE is used to hierarchically organize the 34 criteria classes and to associate normalized weight values through pairwise 
1 comparisons, rank ordering or direct assignments. In our analysis, we directly

2 assigned class weights taken into consideration the frequency ratio of landslides

3 from the French inventory over the criteria classes. Susceptibility was ascertained

4 utilizing the following procedure: First, the French territory (excluding Corsica,

5 the overseas territories and other minor islands) was partitioned into three main

6 physiographic units: (i) mountains, (ii) plains, and (iii) coastal areas. This was

7 done to respect the fact that same criteria classes have a different influence on

8 landslide susceptibility based on their specific physiographic setting. Moreover,

9 coastal regions were treated separately since coastal landslides can hardly be

10 compared to inland mass movements because of their different controlling

11 characteristics. Mountains and plains were outlined using the general criteria

12 proposed by Nordregio (2004). Coastal areas were defined geometrically,

13 constructing a 1-km wide buffer along the coastline.

14 After partitioning the French landslide inventory into three types (i.e., 15 slides, flows and falls), weights for the individual criteria classes (i.e., 13 classes 16 of terrain slope, 24 classes of lithology, and 10 classes of land cover) were 17 assigned for each landslide type. Next, using a pairwise comparison approach

18 similar to the European example, normalized relative weights were assigned to the 19 ensembles of terrain gradient (0.58), lithology (0.28), and land cover (0.13) 20 classes. These weights measure the relative importance of the three geo21 environmental factors, and modulate the weights assigned to the individual 22 criteria classes.. For simplification, the same parameter weights were assigned to 23 the geo-environmental controlling factors for the three different landslide types.

A set of typology-specific susceptibility maps (i.e., for slides, flows and 25 topples) was produced for each physiographic region (i.e., coasts, mountains and 26 plains) using a weighted linear summation of the established weights following 27 (1). The terrain-specific susceptibility maps for each landslide type were spatially 28 combined, and the typology-specific susceptibility indices were classified into 29 four susceptibility levels (very low, low, moderate, and high) using a Jenks 30 natural breaks classification (Jenks 1967). More information on the national level 31 landslide susceptibility map for France can be found in Malet et al. (in revision). 
$1 \quad$ Landslide susceptibility maps

2 Map results of the modelling approach described above for the national-scale

3 susceptibility to falls, flows, and slides are portrayed in Fig. 6A-C. In the three

4 maps, susceptibility is shown in four classes, from very low (VL) to high $(\mathrm{H})$.

5 Visual inspection of Fig. 6A-C shows that the geographical pattern of

6 susceptibility varies for the three considered landslide types. Susceptibility to falls

7 (Fig. 6C) is largest in areas where the terrain is steep and rock slopes are

8 widespread, favouring the occurrence of rock falls, topples, and minor rock slides.

9 Susceptibility to slides (Fig. 6A) is moderate to high in the French Alps and the

10 Pyrenees, and in hilly areas where terrain slope and associations of rock types

11 control the susceptibility to slides. Areas exhibiting a moderate to high

12 susceptibility to landslides of the flow type (Fig. 6B) are widespread in France

13 and more abundant than the corresponding areas for falls and slides. Susceptibility

14 to flows is generally large in areas with soft rocks..

15 Based on the three separate susceptibility zonations for falls, flows and 16 slides (Fig. 6A-C), an attempt was made to produce a single, comprehensive 17 zonation of landslide susceptibility for France (Fig. 6D). For the purpose, the

18 three susceptibility maps prepared for the three landslide types were combined to

19 obtain a single map that considers the susceptibility to all landslide types. This 20 was performed using a very conservative approach (Fig. 6E): for each grid cell, 21 the three different susceptibility values for falls, flows and slides (in four classes) 22 were compared, and the largest cell value was attributed to the grid cell as a 23 measure of the general susceptibility. This association approach was selected to 24 respect the precautionary principle that guides the French legislation on natural 25 hazard and risk assessment, and the production of Risk Prevention Plans 26 (MATE/METL 1999). Inspection of Fig. 6D reveals that the majority of the 27 French territory $(75 \%)$ is classified as having moderate $(31 \%)$ or high $(44 \%)$ 28 susceptibility. The remaining territory $(25 \%)$ is attributed a low $(19 \%)$ or very low $29(6 \%)$ susceptibility. We acknowledge that the significant proportion of territory 30 classified as having a moderate or high susceptibility largely depends on the 31 conservative technique adopted to associate the individual zonations, which 32 favoured the attribution of high values of susceptibility to the individual grid cells.

33 To better illustrate the distribution of the compound susceptibility classes 34 over France we compared the relative spatial proportions of the individual 
1 susceptibility levels in plain and mountain sub-units and the areal percentages of

2 all susceptibility classes for the two physiographic units (Fig. 7A). It can be

3 observed that the three lowest susceptibility classes reveal very similar relative

4 proportions, but the percentages of grid cells attributed to high susceptibility is

5 equal in the plain and the much smaller mountain units. The fact that a much

6 higher area proportion in the mountain unit is attributed to high landslide

7 susceptibility when compared to the plain unit is also illustrated when comparing

8 the areal percentages of all susceptibility classes for the two physiographic units

9 (Fig. 7B). Again, the high spatial extents of terrains classified as highly

10 susceptible to landslides result from the conservative association procedure

11 applied to combine the individual susceptibility estimates for flows, slides and 12 falls.

13 To evaluate the national-scale landslide susceptibility zonation shown in 14 Fig. 6D, we compared the distribution of the areas where landslide susceptibility 15 is considered high (red areas in Fig. 6D) with the distribution of small 16 administrative units (municipalities) where at least one landslide event is reported 17 in the national BDMvT inventory. Results are summarized in Fig. 8, which shows 18 that many municipalities affected by historical landslides were correctly predicted 19 as highly susceptible by the comprehensive national-scale model. However, the 20 susceptibility model also attributes high level of susceptibility to areas where 21 information on historical landslides is not present in the BDMvT inventory. The 22 main cause for this discrepancy is the fact that the BDMvT database is incomplete 23 and has a low accuracy in many regions (departments) in France, especially in 24 highly landslide-prone regions like the Pyrenees or the French Alps (Fig. 8). A possible susceptibility threshold for the delineation of priority areas 26 subjected to the Tier 2 evaluation differs from the value applied at European-level. 27 The conservative association scheme applied to derive the composite 28 susceptibility map for France from the three typology-specific assessments result 29 in a more pessimistic (but probably more reasonable) evaluation, and for this 30 reason we recommend to consider only the highest susceptibility level (44\% of the 31 territory) for a Tier 2 evaluation here (Fig. 8A). 


\section{Italy}

3 For Italy, geo-environmental and distributed landslide information is available to

4 attempt a national-scale, statistically-based, landslide susceptibility zonation as an

5 example for a Tier 2 evaluation. Even though the synoptic assessment described

6 below does not account for differentiation according to landslide typology or

7 terrain physiography, it demonstrates that statistical landslide susceptibility

8 analyses can be conducted over entire nations at small spatial scales if the required

9 geo-environmental (spatial predictors) and thematic (distributed and accurate

10 landslide data) information is available. The example below also incorporates

11 additional spatial data that should be used for Tier 2 assessments, and employs a

12 different mapping unit (municipality) for susceptibility estimations following the

13 general requirements for Tier 2 landslide susceptibility evaluations (Hervás et al.

14 2007). In the Tier 2 example discussed below, only those municipalities identified

15 as susceptible to landslides by the continental Tier 1 evaluation were analyzed.

16 The municipalities were selected following a conservative approach that identifies

17 municipalities having one or more grid cells classified as moderately to very high

18 susceptible by the synoptic continental Tier 1 evaluation as priority areas (82\% of 19 the Italian territory).

\section{Data}

22 The geo-environmental information consists of medium to coarse resolution 23 topographic (elevation), lithological, soil type, and climate data shown in Table 4. 24 Elevation information is represented by a $90 \mathrm{~m} \times 90 \mathrm{~m}$ DEM acquired by the 25 Shuttle Radar Topography Mission (SRTM) in February of 2000, and distributed 26 by the U.S. Geological Survey (http://srtm.usgs.gov/) in 91 adjacent tiles. The DEM 27 was used to obtain raster GIS morphometric maps including (i) maps of 28 descriptive statistics (i.e., minimum, maximum, range, mean, standard deviation) 29 of elevation and terrain gradient (slope), and (ii) a map showing topographic 30 subdivisions i.e., highlands, uplands and lowlands (Guzzetti and Reichenbach 31 1994). Information on rock types was obtained from the Geological Map of Italy 32 published at 1:1M scale by Compagnoni et al. (1976-1983). For the susceptibility 33 modelling, the 145 rock units shown in this map were grouped into 10 main 
1 lithological complexes comprising similar rock types. Information on soil types

2 was obtained from the Soil Map of Italy published at 1:1M scale by Mancini

3 (1966). For the susceptibility analysis, the original soil information shown in the

4 small-scale scale map was grouped into eight classes of soil thickness and 11

5 classes of soil types. Climatic information for Italy, including mean cumulated

6 annual rainfall and mean annual temperature for the period 1961-1990 was

7 obtained from the Centro Nazionale Cartografia Pedologica (L'Abate and

8 Costantini 2004). The landslide information used for susceptibility modelling was

9 the catalogue of historical landslides in Italy compiled by the AVI Project

10 (Guzzetti et al. 1994; Guzzetti and Tonelli 2004). This is the same landslide

11 information used for the evaluation of the synoptic-scale landslide susceptibility

12 assessment for Europe discussed above.

13 To define landslide susceptibility in Italy, the municipality was selected as 14 the mapping unit of reference. Italy is subdivided into 8102 municipalities, 15 administrative subdivisions ranging in size from $0.1 \mathrm{~km}^{2}$ (Atrani, Campania) to $161,285 \mathrm{~km}^{2}$ (Rome) (mean area $=37.3 \mathrm{~km}^{2}$, std. dev. $=50.0 \mathrm{~km}^{2}$ ). For the 6159 $17(76,0 \%)$ municipalities identified as susceptible to landslides by the continental 18 Tier 1 evaluation, we computed from the criteria in Table 4 the following 61 19 variables: (i) 10 variables describing descriptive statistics for terrain morphometry 20 (minimum, maximum, range, mean, standard deviation of elevation and slope), 21 (ii) three variables showing topographic setting (i.e., highlands, uplands, and 22 lowlands), (iii) the percentage of the10 main lithological complexes aggregated 23 from the Geological Map of Italy of Compagnoni et al. (1976-1983), (iv) the 24 percentage of the eight classes of soil thickness and of the 11 classes of soil types 25 derived from the Soil Map of Italy of Mancini (1966), (v) 18 variables describing 26 meteorological and climate conditions obtained through ordinary kriging of the 27 long term annual values of about 1000 reference meteorological stations 28 (L'Abate and Costantini 2004, 29 http://abp.entecra.it/soilmaps/ita/pedoclima30.html), and (vi) one variable for the 30 presence or absence of historical landslide events in the neighbouring 31 municipalities. The presence (or absence) of one or more of the landslides listed in 32 the AVI catalogue (Guzzetti et al. 1994; Guzzetti and Tonelli 2004) in each of the 336159 municipalities selected for the Tier 2 analysis was adopted as the dependent, 34 classification variable for the multivariate modelling. For the purpose, the 
1 landslide information in the historical catalogue was split into two sets: (i) a

2 training set covering the 41-year period 1950-1990 was used to construct (train) a

3 multivariate classification model (7704 landslide events in 2608 municipalities),

4 and (ii) a validation set covering the 11-year period 1991-2001 was used to

5 validate (evaluate) the model prediction skills (10750 landslide events in 2801

6 municipalities).

\section{Methodology}

9 Landslide susceptibility in Italy was determined applying linear discriminant 10 analysis, a consolidated multivariate technique introduced by Fisher (1936) to 11 classify samples into alternative groups on the basis of a set of measurements

12 (Michie et al. 1994; Brown 1998), and commonly adopted by geomorphologists to 13 determine landslide susceptibility at different spatial scales (e.g., Guzzetti et al. 14 1999). For landslide susceptibility assessment, the two groups (G) commonly 15 established, are: (i) mapping units free of landslides $\left(\mathrm{G}_{0}\right.$, municipalities without 16 landslide events), and (ii) mapping units having landslides $\left(\mathrm{G}_{1}\right.$, municipalities 17 with landslide events).

18 The scope of discriminant analysis is to determine the group membership 19 of a mapping unit by finding a linear combination of the geo-environmental 20 variables which maximizes the differences between the populations of stable and 21 unstable mapping units, with minimal error. To obtain this, consider a set of $\mathrm{m}$ 22 environmental variables $\mathrm{v}_{1}, \mathrm{v}_{2}, \ldots, \mathrm{v}_{\mathrm{m}}$ for each mapping unit, $\mathrm{r}$, by means of which 23 it is desired to discriminate the region between the groups of stable $\left(\mathrm{G}_{0}\right)$ and 24 unstable $\left(\mathrm{G}_{1}\right)$ units, and let $\mathrm{Z}$ be the linear combination of the input variables, such as

$$
Z=\beta_{1} v_{1}(r)+\beta_{2} v_{2}(r)+\ldots+\beta_{m} v_{m}(r)
$$

27 For discriminant analysis, the task is to determine the coefficients $\beta_{\mathrm{i}}$ enabling $\mathrm{Z}$ to 28 serve as an index for differentiating between members of the two groups. The 29 relative contribution of each independent geo-environmental variable to the 30 discriminating function can be evaluated by the standardized discriminant 31 function coefficients (SDFC). The SDFC show the relative importance (i.e. the 32 "weight") of each variable as a predictor of slope instability. Variables with large 33 coefficients (in absolute value) are more strongly associated with the presence or 
1 the absence of landslides, with positive and negative coefficients indicating

2 respectively positive and negative correlation with instability within a mapping

3 unit. It should be noted that this model is highly similar to SMCE. However, the

4 important difference is that the coefficients in Eq. 2 are obtained through a

5 quantitative statistical analysis.

$6 \quad$ Through a step-wise procedure, the linear discriminant function selected

718 variables out of the 61 variables described above as the best predictors of the

8 presence (or absence) of historical landslides in the 6159 Italian municipalities, in

9 the training period 1950-1990. The selected geo-environmental variables

10 indicated in Table 5 include seven morphological, three lithological, one soil type,

11 six climate-related, and one variable describing the presence/absence of historical

12 landslides in the neighbouring municipalities.

\section{Landslide susceptibility map}

15 Fig. 9A portrays the landslide susceptibility map obtained for the Italian territory 16 that has been identified as susceptible to landslides by the continental-level Tier 1

17 evaluation. In the map, the individual municipalities are classified based on their

18 probability of pertaining to the group of municipalities that have experienced (or

19 have not experienced) one or more historical landslides listed in the AVI

20 catalogue in the training period 1950-1990. To decide the levels of landslide

21 susceptibility, the inference was made that if a municipality was predicted to have

22 a high or very high probability of containing a historical landslide, the same

23 municipality is expected to have a high (orange) or very high (red) susceptibility,

24 i.e. a high or very high propensity to generate future landslides. Similarly, if a 25 municipality has a low or very low probability of containing a known historical 26 landslide, the same municipality was attributed a low (light green) or very low 27 (green) susceptibility, i.e. a low or very low propensity to generate future 28 landslides. Areas attributed moderate susceptibility in the map (Fig. 9A) represent 29 a special case. These are municipalities for which the linear discriminant model 30 was unable to decide convincingly (i.e. with a probability $\mathrm{P}>|0.55|$ ) if the 31 municipality pertains to the unstable (having historical landslides) or the stable 32 (not having historical landslides) groups. These municipalities are of uncertain 33 attribution and further information is necessary to decide their level of landslide 34 susceptibility. 
1 Overall, the linear discriminant model has classified correctly 3999 2 (64.9\%) of the 6159 Italian municipalities evaluated in the Tier 2 analysis. This is

3 a quantitative measure of the degree of fit of the susceptibility model, i.e. of the

4 ability of the statistical classification procedure to match the geographical 5 distribution of the known historical landslides. Of the correctly classified 6 municipalities, $2272(64.0 \%)$ were classified as unstable (i.e., prone to 7 landsliding) and $1727(66 \%)$ were classified as stable (i.e., not prone to 8 landslides) by the model. With the information above, a contingency table was 9 created that illustrates the significance of the model (Fig. 9B).

10 Inspection of Fig. 9A reveals the geographical distribution of the predicted 11 landslide susceptibility. The Tier 2 model predicts susceptibility to be high to very 12 high in 2369 municipalities (29,3\% of the total number of analyzed muncipalities. 13 In particular, susceptibility is predicted to be very high in the Alps, the Apennines, 14 and in parts of Sicily. Fig. 9A further shows local problems with the national 15 assessment. As an example, the Calabria region, southern Italy, is attributed 16 susceptibility levels lower than expected. This is a consequence of the 17 incompleteness of the historical landslide information in the AVI catalogue in this 18 region.

19 Availability of an independent landslide validation set covering the period 20 1991-2001 allowed evaluating the prediction skill of the susceptibility model. By 21 substituting the model training (1950-1990) dataset with the model validation 22 (1991-2001) dataset, the linear discriminant model classified correctly 3800 $23(61.7 \%)$ of the 6159 municipalities. This is a quantitative measure of the 24 prediction skill of the national-scale susceptibility assessment (e.g., Chung and 25 Fabbri 2003; Guzzetti et al. 2006). Of the 3800 municipalities that were correctly 26 predicted by the model, 1724 were predicted unstable (i.e. landslide prone), and 272076 were predicted stable by the model.

28 As a further quantitative test of the model fitting performance and 29 prediction skills, we prepared ROC curves both for the training set (continuous 30 line in Fig. 9C) and for the validation set (dashed line in Fig. 9C). The resulting 31 quality metric are $\mathrm{AUC}=0.70$ for the training set and $\mathrm{AUC}=0.66$ for the 32 validation set. We consider these values satisfactory with respect to the quality 33 and resolution of the available geo-environmental and landslide information, and 34 the difficulty of the prediction, limited to a 11-year period 1991-2001. 


\section{Discussion}

2 The continental-level Tier 1 assessment presented in this work shows that both

3 thematic information and methods are available to produce a harmonised, small-

4 scale susceptibility map over Europe that allows for the identification of priority

5 areas when evaluated with exemplary national-level landslide inventory data.

6 According to the draft of the European Soil Framework Directive, those priority

7 areas represent terrains that should be subjected to detailed spatial evaluations of

8 soil threats, i.e. landslide susceptibility (EC 2006b). A comparison with already

9 available global and continental landslide susceptibility and hazard zonations

10 alternatively considered for Tier 1 analyses further indicates the advanced validity

11 of the proposed map. However, other European-level landslide susceptibility,

12 hazard and risk zonations as prepared in the framework of the EU-FP7 SafeLand

13 project (Jaedicke et al. 2011; Van Den Eeckhaut et al. 2011) could provide

14 alternatives to the continental-level assessment presented here, if evaluated better.

15 In any case, generalized landslide susceptibility modelling over highly complex

16 areas like Europe generally proves difficult, also when considering the diversity of

17 landslide phenomena. This is also true for the pan-European susceptibility map

18 presented here, as evidenced by the ROC analyses illustrating predictive

19 capabilities that should be improved. A solution may consist in preparing different

20 susceptibility zonations for different climatic and physiographical regions,

21 adopting specific sets of weights decided on regional climato-physiographical

22 conditions.

23 The main reason for selecting an expert-based approach - as opposed to

24 e.g., a statistically based approach - for Tier 1 analyses was the lack of sufficient

25 landslide information. For Europe, a complete coverage of landslide information

26 is not available, and will not be available in the near future. However, information

27 on landslides exists for many countries or regions in Europe (Van Den Eeckhaut

28 and Hervás 2012). Since landslide information is the major prerequisite for all

29 kinds of susceptibility assessments (e.g., van Westen et al. 2009), availability of

30 extended data over Europe will allow determining new and improved weights for

31 the susceptibility criteria considered, especially when a climato-physiographic

32 terrain zoning is introduced. However, it can be suspected that even if more

33 landslide information is collected and harmonised, it will still remain incomplete 34 and inaccurate in many areas. This is illustrated by the Tier 1 application over 
1 France, where many highly landslide prone areas lack distributed landslide data

2 and straightforward, inventory-based statistical assessments are hampered even

3 though a harmonised national-level inventory is available. It can be suspected that

4 both the lack and spatial heterogeneity of landslide information will require expert

5 knowledge in many European regions even in the near future. In turn, more

6 detailed information in areas representative for specific climato-physiographic

7 settings over Europe could allow for calibration of statistical landslide

8 susceptibility models through careful selection of landslide- and landslide-free

9 terrain elements, as recently demonstrated by Van Den Eeckhaut et al. (2011). We

10 suppose that such computations will provide a clue for cross-validation of

11 heuristic assessments through data-driven techniques and will enhance the

12 robustness of the models in the future.

13 The continental-level Tier 1 landslide susceptibility zonation prepared in 14 this work considers all types of landslides. However, the national Tier 1 modelling 15 of landslide susceptibility in France has shown unambiguously that the 16 susceptibility to different major landslide types (i.e., slides, flows, falls/topples) 17 varies geographically. Also future continent-wide Tier 1 landslide susceptibility 18 assessments should be prepared accordingly. However, this will require a 19 typologically separated landslide inventory for model calibration and evaluation.

Where multiple susceptibility assessments are available for different

21 landslide types and climato-physiographic regions, the problem consists in 22 combining the individual assessments into a single (comprehensive) Tier 1

23 landslide susceptibility assessment. The experiment conducted in France adopting 24 a conservative combination through the assignment of the highest susceptibility 25 pixel value obtained for one of the three landslide types, based on the 26 precautionary principle underpinning the French legislation on natural hazards, 27 resulted in a significantly large portion of the territory classified as susceptible to 28 landslides (75\% of the area classified as "high" and "moderate", Fig. 6). Even 29 though this result may be considered unrealistic in places, combinations of 30 individual landslide susceptibility evaluations will most probably always be more 31 pessimistic than generalized assessments which in most cases underestimate the 32 propensity of non-mountainous terrains to generate landslides. We therefore 33 conclude that spatially combined, climato-physiographically and typologically 34 specific susceptibility assessments will offer a better insight in the spatial 
1 distribution of the landslide problem over Europe at the synoptic scale and hence

2 enable a better delineation of priority areas through Tier 1 assessments. However,

3 this requires appropriate spatial association and classification schemes for the

4 combination of specific susceptibility estimates such as e.g. summation or

5 reclassification of typology-specific susceptibility estimates.

For the delineation of priority areas subjected to quantitative Tier 2 7 analyses against areas where no further action has to be taken, appropriate 8 threshold levels have to be defined for any Tier 1 analysis. Our Tier 1 assessments

9 show that the definition of such thresholds may be determined by the kind of Tier 101 analysis, e.g. whether a differentiated or undifferentiated analysis in terms of 11 landslide typology is conducted. In the synoptic continental-level evaluation 12 presented here (Fig. 4), it seems appropriate to use the three highest susceptibility 13 levels (i.e., very high, high, moderate) as a threshold for areas in which Tier 2 14 analyses should be performed. The application of this threshold assigns $36 \%$ of 15 the analysed area as to be subjected to Tier 2. In contrast, the differentiated Tier 1 16 analysis over France (Fig. 6) calls for a rather different susceptibility threshold 17 due to the conservative association method applied to produce the compound 18 susceptibility map. We recommend to exclusively use the highest susceptibility 19 class here (resulting in $44 \%$ of the area subjected to Tier 2) since this is suggested 20 to provide a reliable overview of the main areas known to be prone to landslides. 21 For comparison, the synoptic continental-level Tier 1 assessment with the 22 threshold specified above delineates $33 \%$ of the French continental territory as 23 subjected to Tier 2. Albeit the priority areas defined by both assessments show a 24 good first-order correlation (compare Fig. 4 and 6), this discrepancy is mainly due 25 to the rather different Tier 1 evaluations (e.g., synoptic vs. differentiated) 26 conducted at continental and national levels.

27 Following the general specifications for the assessment of soil threats, Tier 282 analyses should allow to decide on appropriate programmes of measures to 29 evaluate and combat soil threats as proposed in the draft of the Soil Framework 30 Directive (EC 2006b), but should not be considered alternative to Tier 1 in terms 31 of delineation of priority areas (Eckelmann et al. 2006; Hervás et al. 2007). 32 Additionally, a Tier 2 analysis should provide quantitative measures on the spatial 33 distribution of landslide susceptibility, and can incorporate data that is not yet 34 available. We have presented a quantitative, statistical landslide susceptibility 
1 analysis for priority areas in Italy, based on distributed and multitemporal

2 landslide information allowing for establishment and validation of the inventory-

3 based assessment through a multivariate classification technique. The evaluation

4 is based on an administrative mapping unit (municipality), having the advantage

5 of allowing for a direct association between the landslide susceptibility

6 information and societal and (agro)economical data, including population census

7 data. These associations must be considered essential for the effective evaluation

8 of any soil threat at small spatial scales, and therefore we argue that the kind of

9 mapping unit is, together with the application of quantitative evaluation

10 techniques based on distributed landslide information, considered the major

11 specification for Tier 2 analyses. Our Tier 2-compatible analysis over susceptible

12 terrains in Italy therefore demonstrates that such evaluations can be conducted

13 even at small spatial scales if the required geo-environmental and landslide

14 information is available together with a mapping unit of a suitable size.

15 The exemplary Tier 2 analysis presented employs an administrative 16 mapping unit that does not reflect the geo-environmental conditions controlling 17 the geographical and temporal occurrence of landslides in an area. For this reason, 18 further geomorphographic subdivision based on the specific (local) geo19 environmental settings would be required.. Alternatively, the establishment of 20 appropriate geographical management units for the general assessment of soil 21 threats (including landslides) in the context of Tier 2 evaluations may be enforced 22 within the further development of the Soil Thematic Strategy. In any case, 23 application of Tier 2 should not be conducted using terrain units larger than 24 municipalities.

The example for a synoptic Tier 2 evaluation presented here does not 26 account for a differentiation according to landslide typology. However, for future 27 development of the Tier 2 approach, it seems very important to claim for 28 typologically-specific landslide susceptibility evaluations. Since a Tier 2 29 assessment also calls for additional spatial data to assess landslide susceptibility, 30 the common criteria for Tier 2 should be reconsidered in such that the most 31 important geo-environmental factors governing the susceptibility to at least a 32 basic typological landslide differentiation according to slides, falls and flows 33 should be identified and specified, apart from the requirement of distributed 34 landslide inventories in areas subjected to Tier 2. It should also be noted that a 
1 further testing on the compatibility between Tier 1 and Tier 2 at small spatial

2 scales should be conducted for a geomorphological unit (e.g., Alpine chain) rather

3 than on national levels. However, since the required data (distributed landslide

4 information and an appropriate mapping unit) was exclusively available for Italy

5 in this study, this could not be achieved here.

6 Based on the examples shown in this paper, Tier-based assessments may 7 not be considered as strictly scale-dependent. In fact, both Tier 1 and Tier 2 8 compatible assessments can be conducted at several spatial scales as determined

9 by the scale of the input data and the scale/size of the mapping unit of reference.

10 This is demonstrated by the different Tier 1 evaluations presented in this work 11 where the continental-level evaluation uses a $1 \mathrm{~km} \mathrm{x} 1 \mathrm{~km}$ grid cell as a mapping 12 unit, whereas the national-level evaluation for France utilizes a $50 \mathrm{~m}$ x $50 \mathrm{~m}$ grid 13 cell. Both evaluations aim to delineate priority areas and do not necessarily 14 require landslide information to be carried out. In contrast, any Tier 2 evaluation 15 should be based on distributed landslide information and should allow for the 16 decision on measures/implementation plans to mitigate landslides. In this context, 17 it depends on data availability and purpose for the user to perform any of the two 18 Tier evaluations.

\section{Conclusions}

21 After having presented and discussed examples for small-scale landslide 22 susceptibility analyses at continental and national levels, we conclude our 23 contribution specifying the major requirements for future developments of the 24 Tier-based landslide zoning approaches in the context of the European Union's 25 Soil Thematic Strategy.

A Tier 1 landslide susceptibility analysis is aimed at the identification of 27 priority areas (Eckelmann et al. 2006). It should be based on a reduced set of 28 common criteria considering three geo-environmental factors (terrain gradient, 29 lithology, and land cover) and evaluated/validated with representative landslide 30 information (Hervás et al. 2007). Based on a synoptic analysis at the continental 31 level and a differentiated evaluation at the national level for France considering 32 major landslide types and physiographic regions, we conclude that landslide 33 susceptibility can be successfully evaluated for the delineation of priority areas 
1 with the reduced environmental information. However, any synoptic analysis at

2 the continental level can be supposed to give a biased overview on landslide 3 susceptibility since not considering specific landslide types or climato4 physiographic settings. At present, we continue gathering locational and 5 typological information on landslide events in Europe at national and regional 6 levels (Van Den Eeckhaut and Hervás 2012) and elaborating a climato7 physiographic terrain delineation allowing for specification of model regions 8 throughout Europe. This will allow for a differentiated Tier 1 modelling approach 9 at the continental level. First preliminary results are promising and indicate that a 10 more advanced continental scale susceptibility evaluation suitable for better 11 delineation of priority areas can be elaborated in the future (Günther et al. in 12 press).

13 In the context of a Tier 2 landslide susceptibility evaluation to be 14 conducted in priority areas identified by Tier 1, our Tier 2 attempt for Italy shows 15 that quantitative, statistical landslide susceptibility evaluations can be conducted 16 even at small spatial scales, provided that enhanced geo-environmental data on 17 landslide controlling factors, together with (most importantly) distributed and 18 harmonised landslide data is available. Considering the latter, we conclude that 19 Tier 2 areas as identified by Tier 1 should delineate regions where distributed, 20 multi-temporal landslide inventory data with typological information should be 21 gathered as required for inventory-based, statistical Tier 2 evaluations. For the 22 exemplary Tier 2 evaluation presented here, we recommend a small administrative 23 mapping unit (municipality) for spatial evaluation since the decision on 24 measures/implementation plans based on Tier 2 analysis to assess the landslide 25 threat requires an association of landslide susceptibility with (agro) economic or 26 population-related census data. However, since geo-environmental conditions are 27 in most cases not associated with administrative units, we conclude that the 28 definition of suitable Tier 2 mapping units should be enforced within the further 29 development of the Soil Thematic Strategy for general Tier 2-based assessments 30 of soil threats. Furthermore, we conclude that Tier 2 evaluations in terms of 31 landslides should be conducted individually for at least three major types of 32 landslides (e.g., slides, flows and falls).

33 Finally, it is important to mention that the spatial assessment of rather 34 localized soil threats like landslides cannot be sufficiently addressed through 
1 small-scale evaluations as the Tier-based concept proposed in the framework of

2 the Soil Thematic Strategy. Therefore, it does not substitute landslide-specific

3 statistical or physically-based susceptibility modelling in local, highly landslide

4 affected areas as indicated by Tier 2 (i.e., "Tier 3", Hervás et al. 2007) necessary

5 for local landslide mitigation plans.

\section{Acknowledgements}

8 This work was conducted in the framework of the activities of the European

9 Landslide Expert Group on "Guidelines for Mapping Areas at Risk of Landslides

10 in Europe" (http://eusoils.jrc.ec.europa.eu/library/themes/landslides/wg.html), and

11 of the International Consortium on Landslides project IPL-162 "Tier-based 12 harmonised approach for landslide susceptibility mapping over Europe". We 13 thank the other members of the European Landslide Expert Group (J. Chaćon, P. 14 Hobbs, O. Maquaire, A. Pasuto, E. Poyiadji, F. Tagliavini, A. Trigilia) for all the 15 fruitful discussions. We are indebted to D. Kirschbaum Bach (NASA) for 16 providing the portion for Europe of the global landslide susceptibility map of 17 Hong et al. (2007). We thank L. Montanarella (JRC) and R. Baritz (BGR) for the 18 support. We also like to thank two anonymous reviewers and the journal editor for 19 their valuable comments that helped to improve the presentation. FG and PR 20 supported by the EU-FP7 DORIS project (http://www.doris-project.eu/), EC 21 Contract n. 242212.

\section{References}

Asch K (2005) The 1:5 Million International Geological Map of Europe and Adjacent Areas (IGME 5000). Bundesanstalt für Geowissenschaften und Rohstoffe, Hannover, Germany

Ayalew L, Yamagishi H, Ugawa N (2004) Landslide susceptibility mapping using GIS-based weighted linear combination, the case in Tsugawa area of Agano River, Niigata Prefecture, Japan. Landslides 1:73-81 assessment techniques using GIS in the Tirajana basin, Gran Canaria Island, Spain. International Journal of Applied Earth Observation and Geoinformation 2:9-23 
BRGM (2005) The Geological Map of France 1:1 Million. Bureau de Recherches Géologiques et Minières, Paris, France

Brown CE (1998) Applied Multiple Statistics in Geohydrology and Related Sciences. SpringerVerlag, New York

Castellanos Abella EA, van Westen C (2008) Qualitative landslide susceptibility assessment by multicriteria analysis: a case study from San Antonio del Sur, Guantánamo, Cuba. Geomorphology 94:453-466

Chung C-JF, Fabbri AG (2003) Validation of Spatial Prediction Models for Landslide Hazard Mapping. Natural Hazards 30:3 451-472

Committee on the Review of the National Landslide Hazards Mitigation Strategy (2004) Partnerships for reducing landslide risk: assessment of the National Landslide Hazards Mitigation Strategy. National Academies Press, Washington DC

Compagnoni B, Damiani AV, Valletta M, Finetti I, Cirese E, Pannuti S, Sorrentino F, Rigano C (eds) (1976-1983) Carta Geologica d'Italia. Servizio Geologico d'Italia, Stabilimento Salomone, Rome, scale 1:500,000, 5 sheets

EC 2006a Thematic Strategy for Soil Protection. COM(2006)231 final. Commission of the European Communities, Brussels, Belgium

EC 2006b Proposal for a Directive of the European Parliament and of the Council establishing a framework for the protection of soil and amending Directive 2004/35/EC. $\operatorname{COM}(2006) 232$ final. Commission of the European Communities, Brussels, Belgium EC 2009. A Community approach on the prevention of natural and man-made disasters. $\operatorname{COM}(2009) 82$ final, 23.2.2009, Brussels, Belgium

EC 2010. Risk Assessment and Mapping Guidelines for Disaster Management. SEC(2010) 1626 final, 21.12.2010, Brussels, Belgium

EC 2012. The implementation of the Soil Thematic Strategy and ongoing activities. Report from the Commission to the European Parliament, the Council, the European Economic and Social Committee and the Committee of the Regions, COM(2012) 46, Brussels, Belgium.

Eckelmann W, Baritz R, Bialousz S, Bielek P, Carre F, Houskova B, Jones RJA, Kibblewhite MG, Kozak J, Le Bas C, Toth G, Varallyay G, Yli Halla M, Zupan M (2006) Common criteria for risk area identification according to soil threats. European Soil Bureau Research Report No. 20, EUR 22185 EN. Office for Official Publications of the European Communities, Luxembourg

Evans E, Pennington C, Foster F, in press. Mapping a nation's landslides: a novel multistage methodology. Proceedings of the 2nd World Landslide Forum, 3-9 October 2011, Rome, Italy

Fawcett T (2006) An introduction to ROC analysis. Pattern Recog Lett 27:861-874

Fell R, Corominas J, Bonnard C, Cascini L, Leroi E, Savage WZ (2008) Guidelines for landslide susceptibility, hazard and risk zoning for land use planning. Eng Geol 102:85-98

Figueira J, Greco S, Ehrgott M (2005) Multiple Criteria Decision Analysis: State of the Art Surveys. Springer-Verlag, New York 
Finke P, Hartwich R, Dudal R, Ibàñez J, Jamagne M, King D, Montanarella L, Yassoglou N (2001) Georeferenced soil database for Europe, Manual of procedures, Version 1.1. European Soil Bureau Research Report No. 5, EUR 18092 EN. Office for Official Publications of the European Communities, Luxembourg

Fisher RA (1936) The use of multiple measurements in taxonomic problems. Annals of Eugenics 7:179-188

Foster C, Gibson A, Wildman G (2008) The new national landslide database and landslide hazard assessment of Great Britain. Proceedings of the First World Landslide Forum, Tokyo, 1821 November 2008, pp 203-206

Glade T, Anderson MG, Crozier MJ (eds) (2005) Landslide risk assessment. John Wiley

Gorsevski PV, Jankowski P, Gessler PE (2006) An heuristic approach for mapping landslide hazard by integrating fuzzy logic with analytic hierarchy process. Control Cybern 35(1):121-146

Guzzetti F, Carrara A, Cardinali M, Reichenbach P (1999) Landslide hazard evaluation: an aid to a sustainable development. Geomorphology 31:181-216

Guzzetti F, Cardinali M, Reichenbach P (1994) The AVI Project: A bibliographical and archive inventory of landslides and floods in Italy. Environ Manag 18:623-633

Guzzetti F, Reichenbach P (1994) Toward the definition of topographic divisions of Italy. Geomorphology 11:57-74

Guzzetti F, Tonelli G (2004) Information system on hydrological and geomorphological catastrophes in Italy (SICI): a tool for managing landslides and flood hazards in Italy. Nat Hazards Earth Syst Sci 4:213-232

Guzzetti F, Reichenbach P, Ardizzone A, Cardinali M, Galli M (2006) Estimating the quality of landslide susceptibility models. Geomorphology 81:166-184

Günther A, Reichenbach P, Hervás J (2008) Approaches for delineating areas susceptible to landslides in the framework of the European Soil Thematic Strategy. Proceedings of the First World Landslide Forum, Tokyo, 18-21 November 2008, pp. 235-238

Günther A, Van Den Eeckhaut M, Reichenbach P, Hervás J, Malet JP, Foster C, Guzzetti F, in press. New developments in harmonized landslide susceptibility mapping over Europe in the framework of the European Soil Thematic Strategy. Proceedings of the 2nd World Landslide Forum, 3-9 October, 2011, Rome, Italy

Heineke HJ, Eckelmann W, Thomasson AJ, Jones RJA, Montanarella L, Buckley B (eds) Land Information Systems: Developments for planning the sustainable use of land resources. European Soil Bureau Research Report No. 4, EUR 17729 EN. Office for Official Publications of the European Communities, Luxembourg

Hervás J, Günther A, Reichenbach P, Chacón J, Pasuto A, Malet J-P, Trigila A, Hobbs P, Maquaire O, Tagliavini F, Poyiadji E, Guerrieri L, Montanarella L (2007) Recommendations on a common approach for mapping areas at risk of landslides in Europe. In: Hervás J (ed), Guidelines for Mapping Areas at Risk of Landslides in Europe. Proceedings Experts Meeting, Ispra, Italy, 23-24 October 2007. JRC Report EUR 23093 EN. Office for Official Publications of the European Communities, Luxembourg 
Hong Y, Adler R, Huffman G (2007) Use of satellite remote sensing data in the mapping of global landslide susceptibility. Nat. Hazards 43:245-256.

Jaedicke C, Van Den Eeckhaut M, Nadim F, Hervás J, Kalsnes B, Smith T, Tofani V, Ciurean R, Winter M (2011) Identification of landslide hazard and risk "hotspots" in Europe. Geophysical Research Abstracts 13, EGU2011-10398

Jenks GF (1967) The data model concept in statistical mapping. International Yearbook of Cartography 7:186-190

Kirschbaum DB, Adler R, Hong Y, Lerner-Lam A (2009) Evaluation of a preliminary satellitebased landslide hazard algorithm using global landslide inventories. Nat. Hazards Earth Syst. Sci. 9:673-686

L'Abate G, Costantini EAC (2004). GIS pedoclimatico d'Italia. Progetto PANDA. Istituto Sperimentale Studio e Difesa del Suolo, Centro Nazionale Cartografia Pedologica. Firenze, Italia. CD-Rom (http://abp.entecra.it/soilmaps/ita/pedoclima3.html)Mancini F (ed) (1966) Soil map of Italy. Società Geografica, A.GA.F-A. and R. Senatori Publisher, scale $1: 1,000,000$

Malet JP, Thiery Y, Puissant A, Hervás J, Günther A, Grandjean G (2009). Landslide susceptibility mapping at 1:1M scale over France: exploratory results with a heuristic model. In: Malet J-P, Remaitre A, Boogard TA (eds): Proceedings of the International Conference on Landslide Processes: from Geomorphologic Mapping to Dynamic Modelling, Strasbourg, France, CERG Editions, pp 315-320

Malet JP, Puissant A., Mathieu A, Van Den Eeckhaut M, Fressard M, in revision. Landslide susceptibility assessment at 1:1M scale for France. Landslides, 15p

Mason SJ, Graham NE (2002) Areas beneath the relative operating characteristics (ROC) and relative operating levels (ROL) curves: Statistical significance and interpretation. Q J Royal Meteo Soc 128:2145-2166

MATE/METL (1999) Plan de Prévention des Risques (PPR) - Risques de Mouvements de terrain. Guide Méthodologique. Ministère de l'Aménagement du Territoire et de l'Environnement (MATE), Ministère de l'Equipement des Transports et du Logement (METL), La Documentation Française, Paris, 45pp

Metz CE (1978) Basic principles of ROC analysis. Seminars in Nuclear Medicine, 8:283-298

Michie D, Spiegelhalter DJ, Taylor CC (eds) (1994) Machine Learning, Neural and Statistical Classification. Internet version (http://www.amsta.leeds.ac.uk/ charles/statlog/)

Mora S, Vahrson W (1994) Macrozonation methodology for landslide hazard determination. Bull Assoc Eng Geol 31(1):49-58

35 Nadim F, Kjekstad O, Peduzzi P, Herold C, Jaedicke C (2006) Global landslide and avalanche 36 hotspots. Landslides 3:159-173.

37 Nordregio (2004) Mountain Areas in Europe: Analysis of mountain areas in EU member states, acceding and other European countries. Brussels: Final Report EC Project No 
Panagos P, Van Liedekerke M, Jones A, Montanarella L (2012) European Soil Data Centre:

Response to European policy support and public data requirements. Land Use Policy 29(2):329-338

Remondo J, González-Díez A, Díaz de Terán JR, Cendrero A, Fabbri A, Chung CJF (2003)

Validation of landslide susceptibility maps; examples and applications from a case study in Northern Spain. Nat Hazards 30(3):437-449

Rudolf B, Beck C, Grieser J, Schneider U (2005) Global precipitation analysis products. Deutscher Wetterdienst, Offenbach a. M., Germany

9 Saaty T (1980) The Analytical Hierarchy Process. McGraw Hill, New York

10 Saaty T, Vargas LG (1984) Comparison of eigenvalue and logarithmic least squares and least squares methods in estimating ratios. Mathematical Modelling 5: 309-324.

Schmidt-Thomé P (2006) Natural and technological hazards and risks affecting the spatial development of European regions. Geol. Survey of Finland, Special Paper, 42, 17-63

Trigila A, Iadanza C, Spizzichino D (2010) Quality assessment of the Italian Landslide Inventory using GIS processing. Landslides 7, 455-470

Van Den Eeckhaut M, Hervás J (2012) State of the art of national landslide databases in Europe and their potential for assessing landslide susceptibility, hazard and risk. Geomorphology 139-140:545-558

\section{Figure Captions}

Fig. 1 Location and extent of study areas

37 Fig. 2 Spatial data used for the synoptic-scale analysis of landslide susceptibility in Europe grouped into five classes. (A) Terrain slope, obtained from the global GTOPO 30 terrain elevation 
1 information of the Soil Geographical Database of Eurasia. (C) Land cover information in five classes, obtained from the PELCOM dataset

3 Fig. 3 Landslide inventory maps for three European countries. (A) National landslide database for

4 France (BDMvT) showing 17,598 landslides (June 2010). (B) National Landslide Database for

5 Great Britain, showing 15,897 landslides (October 2011). (C) National archive of historical

6 landslides in Italy, compiled by the AVI project, showing 15,503 landslides for the period 1950 -

72001

8 Fig. 4 Basic Tier 1 landslide susceptibility assessment for Europe. (A) Synoptic-scale landslide

9 susceptibility map. (B) Histogram showing the frequency distribution of the computed values of

10 the normalized landslide susceptibility index S in Europe and pie charts reflecting total area and

11 landslide frequencies of the five susceptibility levels. (C) Receiver Operating Characteristics

12 (ROC) curves of susceptibility estimates and slope raster for three countries with landslide

13 information and for the whole analysed area using the combined inventory information

14 Fig. 5 Continental scale and global scale landslide susceptibility assessments. (A) ESPON

15 landslide hazard zonation of Schmidt-Thomé (2006). (B) Portion of Europe of the global landslide

16 susceptibility map of Hong et al. (2007). (C) Portion of Europe of Global landslide "hotspot" map

17 of Nadim et al. (2006), without the four lowest susceptibility classes. (D) ROC plots comparing

18 the performance of the different susceptibility zonations against the distribution of landslides in

19 France (Figure 3A), Great Britain (Figure 3B), and Italy (Figure 3C)

20 Fig. 6 Differentiated Tier 1 landslide susceptibility assessment for France. (A-C) Individual

21 landslide susceptibility maps for slides, flows, and falls. (D) Compound landslide susceptibility

22 map. (E): Association method employed to produce the compound susceptibility map from the

23 typology-specific maps

24 Fig. 7 Distribution of susceptibility classes of the compound Tier 1 landslide susceptibility map

25 for France. (A) Relative proportions of plain and mountain areas in the different susceptibility

26 classes. (B) Areal percentages of susceptibility levels in plain and mountain areas. Coastal areas

27 were not analysed here due to their small spatial extent ( $0.15 \%$ of study area)

28 Fig. 8 Evaluation of the differentiated Tier 1 susceptibility assessment in France: (A) Compound

29 landslide susceptibility map classified in susceptible and non susceptible areas. (B) Representation

30 of municipalities (red dots) affected by at least one landslide event

31 Fig. 9 Tier 2 landslide susceptibility assessment for Italy. (A) Map showing municipalities

32 classified by the multivariate statistical analysis (colour coded: municipalities identified as priority 33 areas by the continental-level evaluation in Fig. 4; gray : municipalities outside the priority areas).

34 (B) Confusion matrix showing municipalities with/without landslide events against the prediction

35 from the statistical model. (C) Analysis of the prediction skill of the landslide susceptibility model.

36 The continuous ROC curve shows the model fitting performance (AUC $=0.70$ ); the dashed line

37 shows the prediction-rate curve $(\mathrm{AUC}=0.66)$ obtained considering the number of events of the

38 landslide validation set 
Author reply letter

Manuscript LASL-461, Version 2

"Tier-based approaches for landslide susceptibility assessment in Europe"

A. Günther et al.

Dear Editor,

Thank you very much for the re-evaluation of our manuscript. We highly appreciate the comments and have revised the manuscript accordingly, together with additional checking of typos and language. We hope that this improved version can be accepted.

Sincerely Yours,

Andreas Günther (on behalf of all authors)

\section{Reply to comments}

"Page 2 (abstract), line 15. "a historical ..." (not "an historical")

Corrected.

"ibid, line 16. doubled commas"

Corrected.

"Page 23, line 7 and page 24, line 2. First time you right "6159 Italian municipalities?? second time "6160 Italian municipalities?? What No is correct?".

It is 6159 municipalities, we have corrected that throughout.

"Page 23, line 9 (+ Table 5). One soil type. Is it correct that only one siol type is included? Are other types of soils indifferent for landsliding? And what about soil thickness? May be I'm wrong, but in Table 4 this parameter is indicated"

In Table 4, the spatial criteria used for the Tier 2 analysis are indicated, from which 61 variables for the statistical modelling were derived. They are outlined on page 21. In Table 5 and the paragraph at page 23 are listed only those variables that have been selected by the stepwise procedure. We have made this clearer now in the "Data" and "Methodology" sections describing the Tier 2 model on page 20-23. 
In a stepwise discriminant function analysis, a model of discrimination is built step-bystep. Specifically, at each step variables are reviewed and evaluated to determine which one will contribute most to the discrimination between groups. The Wilks' Lambda is the statistical procedure that we have selected in SPSS to add or remove variables from the analysis. 
Click here to download Table: Table1_rev1.docx

Table 1 Landslide susceptibility criteria used for the synoptic-scale landslide susceptibility model and associated terrain zonation for Europe. The number of classes corresponds to expert-based susceptibility reclassification of the thematic variables

\begin{tabular}{llccc}
\hline Factor & \multicolumn{1}{c}{ Source } & Scale & Resolution & Classes \\
\hline Slope angle & GTOPO30 & $1: 1 \mathrm{M}$ & $1 \times 1 \mathrm{~km}$ & 5 \\
Lithology & European Soil Database & $1: 1 \mathrm{M}$ & vector map & 5 \\
Land cover & PELCOM & $1: 1 \mathrm{M}$ & $1 \times 1 \mathrm{~km}$ & 5 \\
\hline
\end{tabular}


Table 2 Weights attributed to the landslide susceptibility criteria used for the assessment of landslide susceptibility in Europe through an Analytic Hierarchy Process (AHP) technique

\begin{tabular}{lclc}
\hline Factor & $\begin{array}{c}\text { Factor } \\
\text { weight }\end{array}$ & Class & $\begin{array}{c}\text { Class } \\
\text { weight }\end{array}$ \\
\hline Slope angle & 0.64 & $<1^{\circ}$ & 0.07 \\
& & $1 \leq 2^{\circ}$ & 0.13 \\
& & $\leq 5^{\circ}$ & 0.20 \\
& $5 \leq 15^{\circ}$ & 0.27 \\
& & $>15^{\circ}$ & 0.33 \\
\hline Lithology & 0.26 & Organic/detrital & 0.07 \\
& & (Glacio)fluvial/sandy/loamy & 0.13 \\
& & Volcanic/crystalline & 0.20 \\
& & Schists/alluvium/colluvium & 0.27 \\
& & Clayey/flyschoid/calcareous & 0.33 \\
\hline Land cover & 0.10 & Urban/wetlands & 0.07 \\
& & Arable/shrubs & 0.13 \\
& & Crops/barren & 0.20 \\
& & Coniferous/mixed forests & 0.27 \\
& & Grassland/deciduous forests & 0.33 \\
\hline
\end{tabular}


Click here to download Table: Table3_rev1.docx

Table 3 Spatial criteria used for the national-scale Tier 1 landslide susceptibility model for France. The number of classes is the result of a reclassification of the original thematic variables

\begin{tabular}{|c|c|c|c|c|}
\hline Factor & Source & Scale & Resolution & Classes \\
\hline Slope & IGN DEM (BD-Alti®) & $1: 100,000$ & $50 \times 50 \mathrm{~m}$ & 13 \\
\hline $\begin{array}{l}\text { Soil parent } \\
\text { material }\end{array}$ & BRGM Geological Map, $6^{\text {th }}$ ed. & $1: 1 \mathrm{M}$ & vector map & 24 \\
\hline Land cover & Corine Land Cover & $1: 100,000$ & $50 \times 50 \mathrm{~m}$ & 10 \\
\hline
\end{tabular}


Table 4 Spatial criteria used for the Tier 2 landslide susceptibility model in priority areas of Italy. The number of classes is the result of a reclassification of the original thematic variables

\begin{tabular}{|c|c|c|c|c|}
\hline Factor & Source & Scale & Resolution & Classes \\
\hline Elevation & SRTM & & $90 \times 90 \mathrm{~m}$ & n.a. \\
\hline Slope & SRTM & & $90 \times 90 \mathrm{~m}$ & n.a. \\
\hline Lithology & $\begin{array}{l}\text { Compagnoni et al. (eds) } \\
\text { (1976-1983) }\end{array}$ & $1: 1 \mathrm{M}$ & vector map & 10 \\
\hline Soil thickness & Mancini (ed) (1966) & $1: 1 \mathrm{M}$ & vector map & 8 \\
\hline Soil type & Mancini (ed) (1966) & $1: 1 \mathrm{M}$ & vector map & 11 \\
\hline $\begin{array}{l}\text { Mean cumulated annual } \\
\text { rainfall }\end{array}$ & $\begin{array}{l}\text { L'Abate and Costantini } \\
(2004)\end{array}$ & & & 9 \\
\hline $\begin{array}{l}\text { Mean annual } \\
\text { temperature }\end{array}$ & $\begin{array}{l}\text { L'Abate and Costantini } \\
(2004)\end{array}$ & & & 9 \\
\hline $\begin{array}{l}\text { Landslide in the } \\
\text { neighboring } \\
\text { municipalities }\end{array}$ & AVI catalogue & & & 2 \\
\hline
\end{tabular}


Table 5 List of the 18 variables entered in the Tier 2 discriminant model of landslide susceptibility in Italy. Positive coefficients are correlated to the presence of landslides. Negative coefficients are correlated to the absence of landslides

\begin{tabular}{|c|c|c|}
\hline Factor & Variable description & $S D F C$ \\
\hline \multirow[t]{7}{*}{ Morphology } & Municipality mean elevation & -.443 \\
\hline & $\begin{array}{l}\text { Standard deviation of municipality } \\
\text { elevation }\end{array}$ & -.724 \\
\hline & Municipality minimum slope angle & -.206 \\
\hline & Municipality mean slope angle & .243 \\
\hline & $\begin{array}{l}\text { Standard deviation of municipality slope } \\
\text { angle }\end{array}$ & -.647 \\
\hline & Municipality slope range & 1,070 \\
\hline & Municipality elevation range & 1,125 \\
\hline \multirow[t]{3}{*}{ Lithology } & Continental deposits & -.252 \\
\hline & Sandstone & .132 \\
\hline & Limestone & -.261 \\
\hline Soil Type & Brown soils & .140 \\
\hline \multirow[t]{6}{*}{ Climate } & Mean annual temperature (range 9.5-12.0) & .123 \\
\hline & $\begin{array}{l}\text { Mean annual temperature (range 12.0- } \\
13.5 \text { ) }\end{array}$ & .270 \\
\hline & $\begin{array}{l}\text { Mean annual temperature (range 13.5- } \\
15.0 \text { ) }\end{array}$ & .260 \\
\hline & $\begin{array}{l}\text { Mean annual temperature (range 17.7- } \\
\text { 20.0) }\end{array}$ & -093 \\
\hline & Annual rainfall (range 698-809) & -.133 \\
\hline & Annual rainfall (range 973-1213) & -.116 \\
\hline Neighboring & $\begin{array}{l}\text { Historical landslide event in the neighbor } \\
\text { municipality }\end{array}$ & .190 \\
\hline
\end{tabular}


Figure1

Click here to download Figure: Figure1_rev1.docx

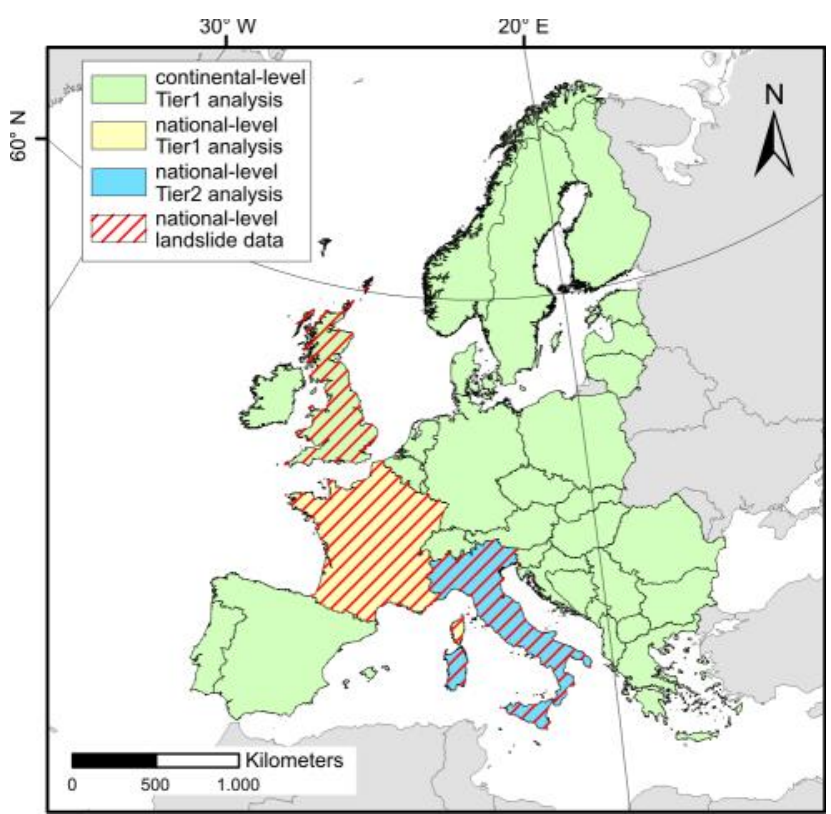

Figure 1 
Figure2

Click here to download Figure: Figure2_rev1.docx

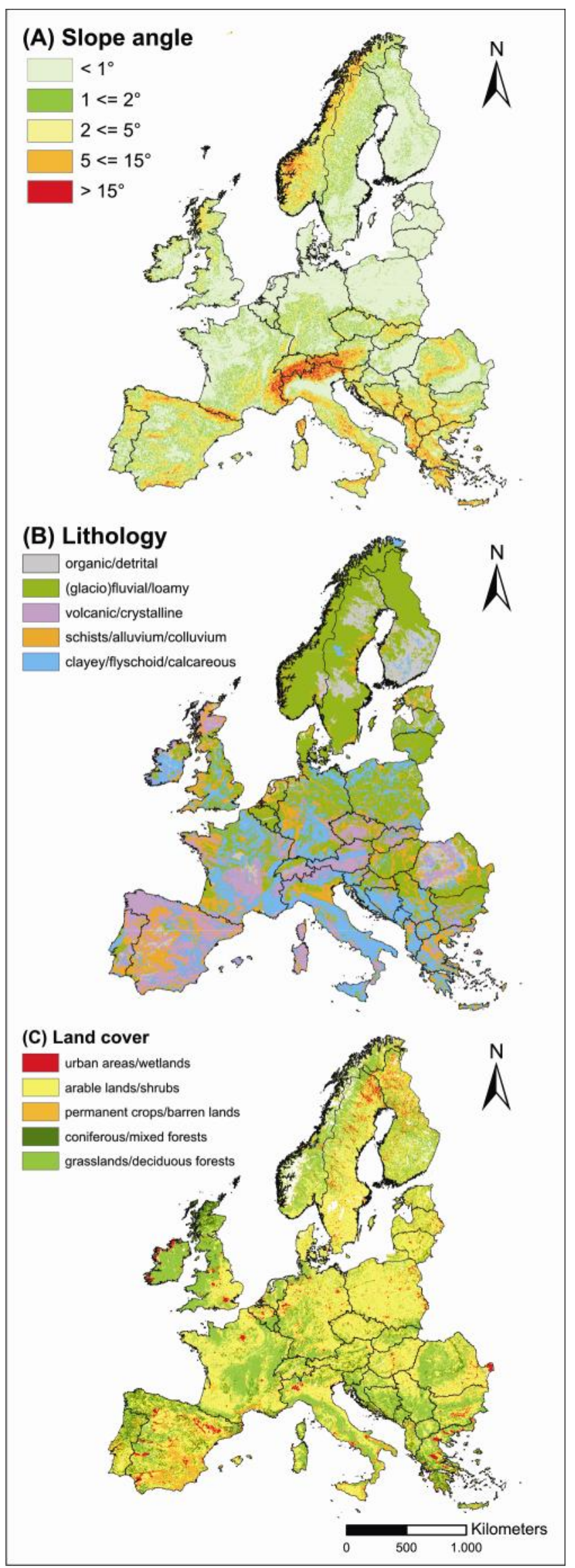

Figure 2 

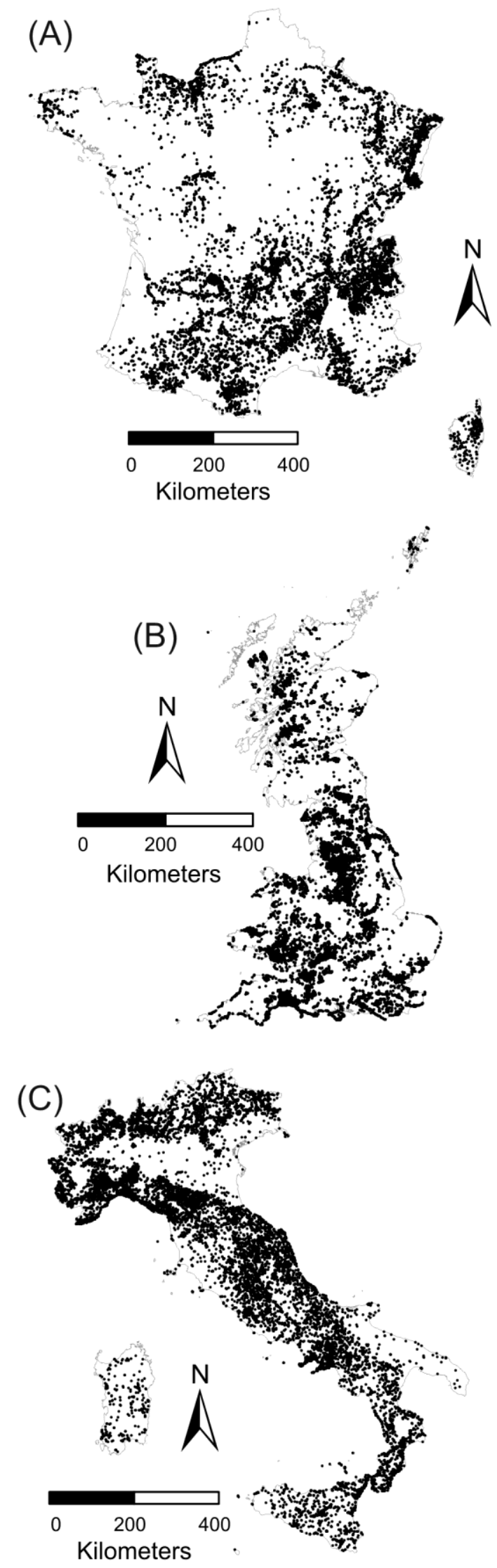

Figure 3 


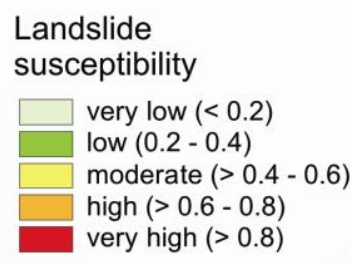

(A)

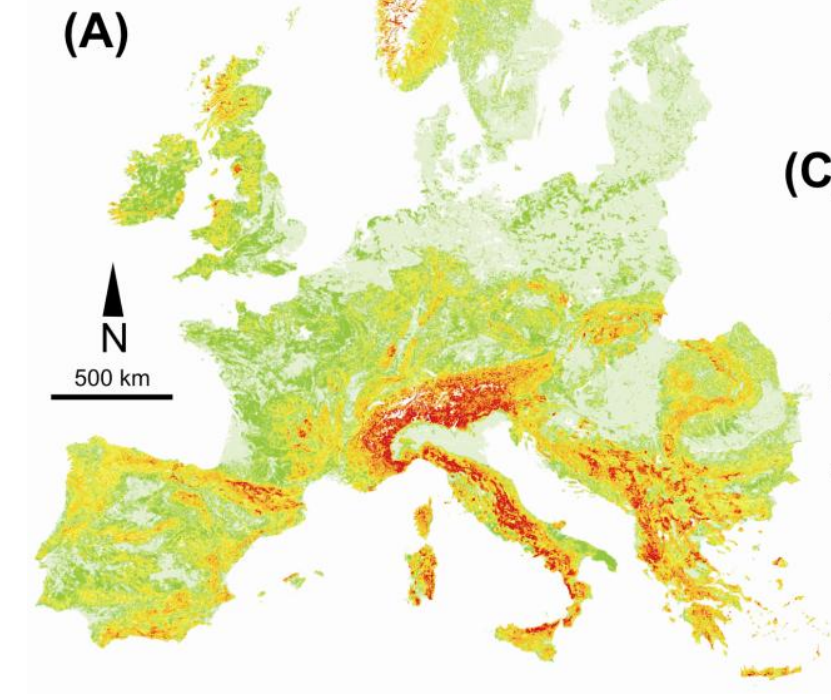

(B)

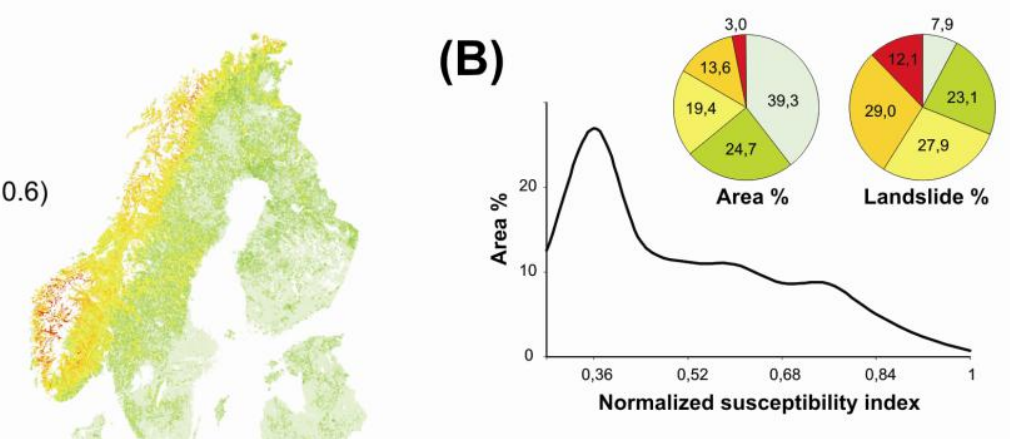

(C)

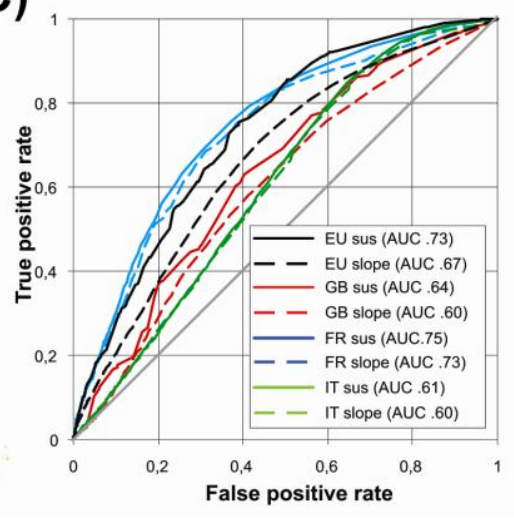

Figure 4 


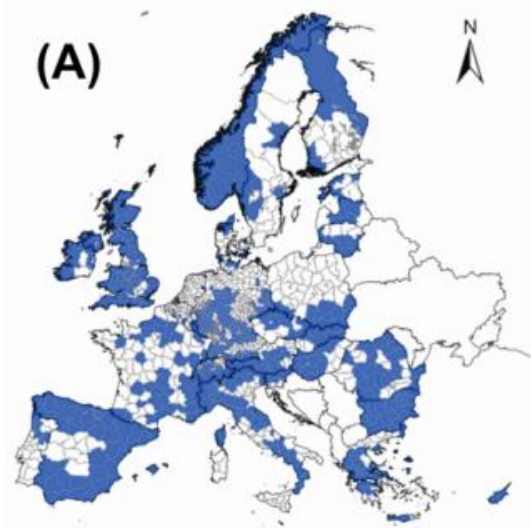

Nuts 3 units with landslide hazard

(Schmidt-Thomé, 2006)

Low hazard

High hazard

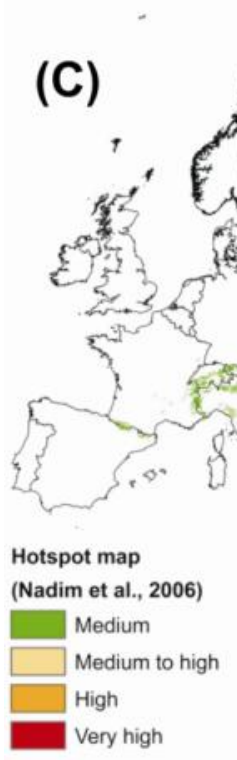

Figure 5

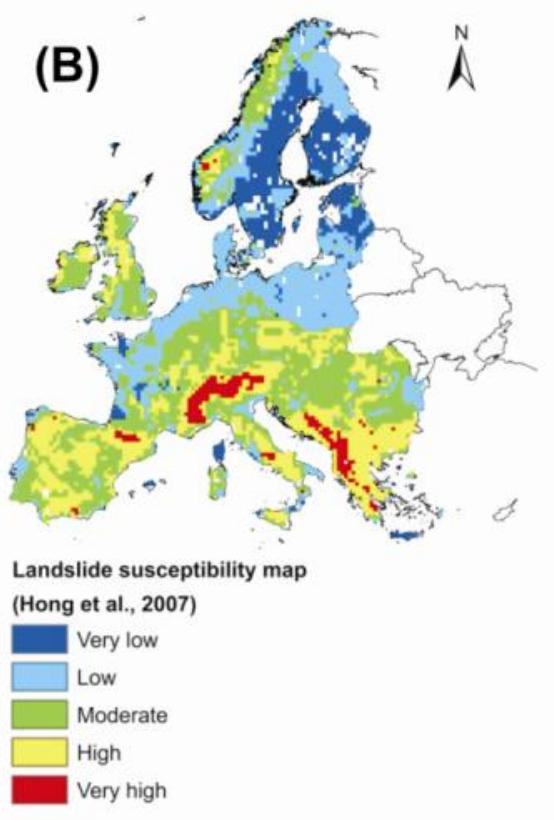

(D)

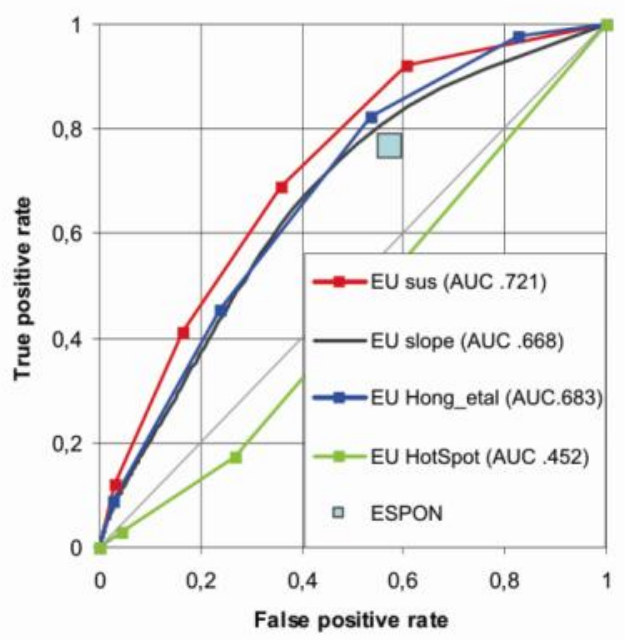



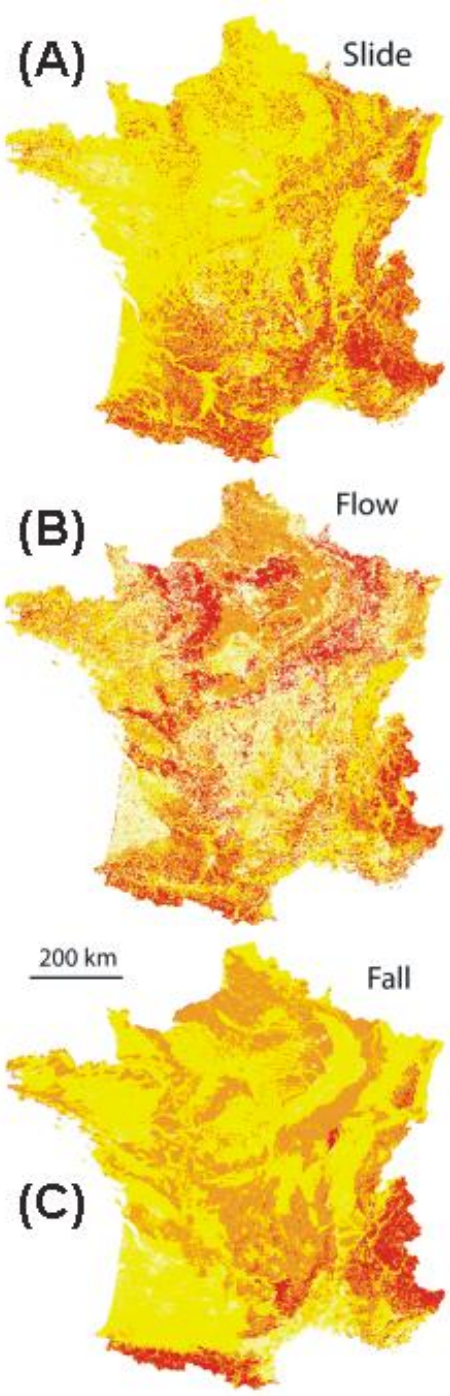

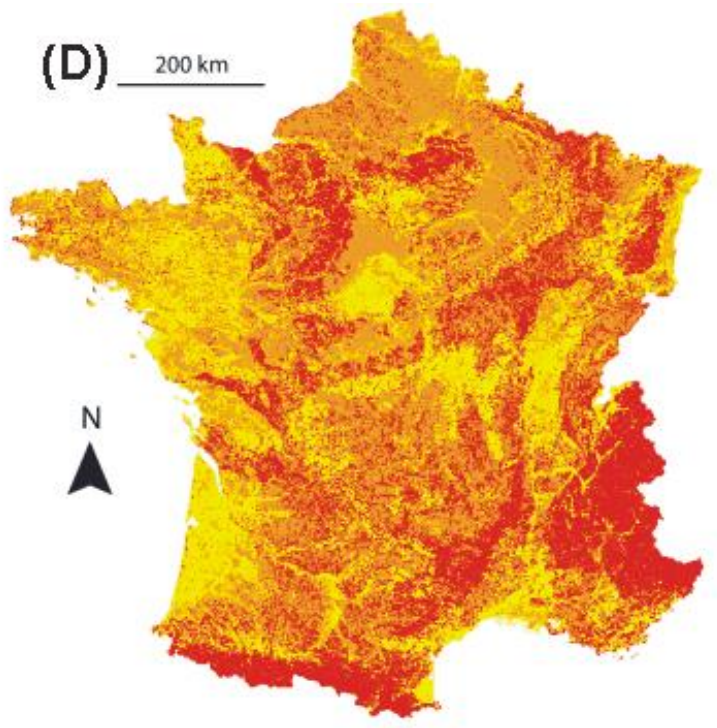

Susceptibility levels

High ( $>=0.8$ )

Moderate $(>0.5-<0.8)$

Low $(>0.2-<=0.5)$

Very low $(<=0.2)$

(E)

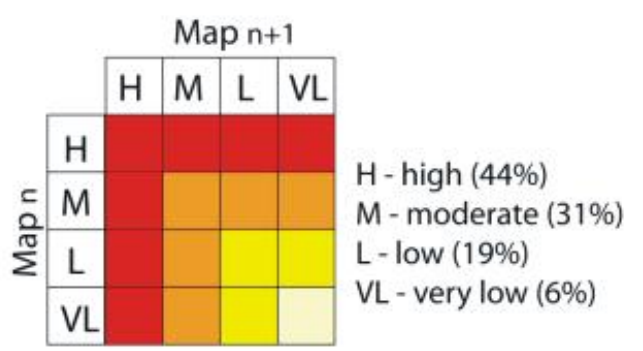

Figure 6 
Click here to download Figure: Figure7_rev1.docx

(A)
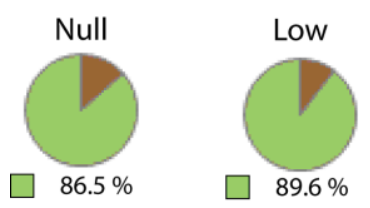

$13.5 \%$

$\square \quad 10.4 \%$

(B)

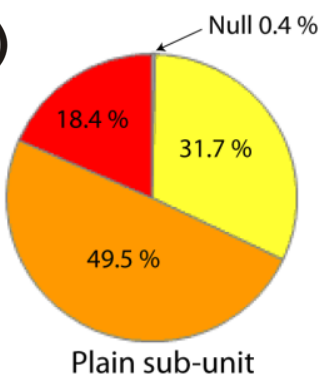

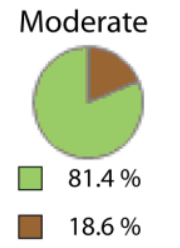

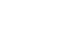

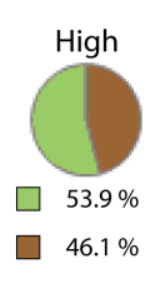

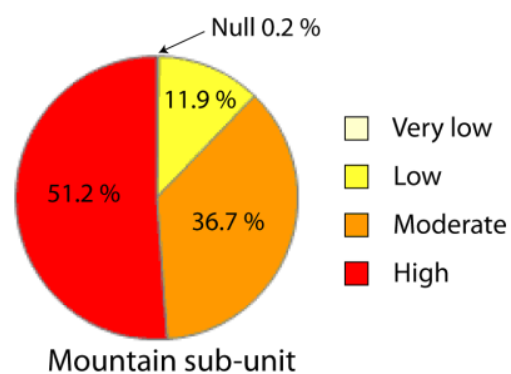

Figure 7

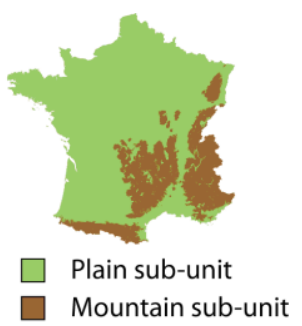


Figure8

Click here to download Figure: Figure8_rev1.docx

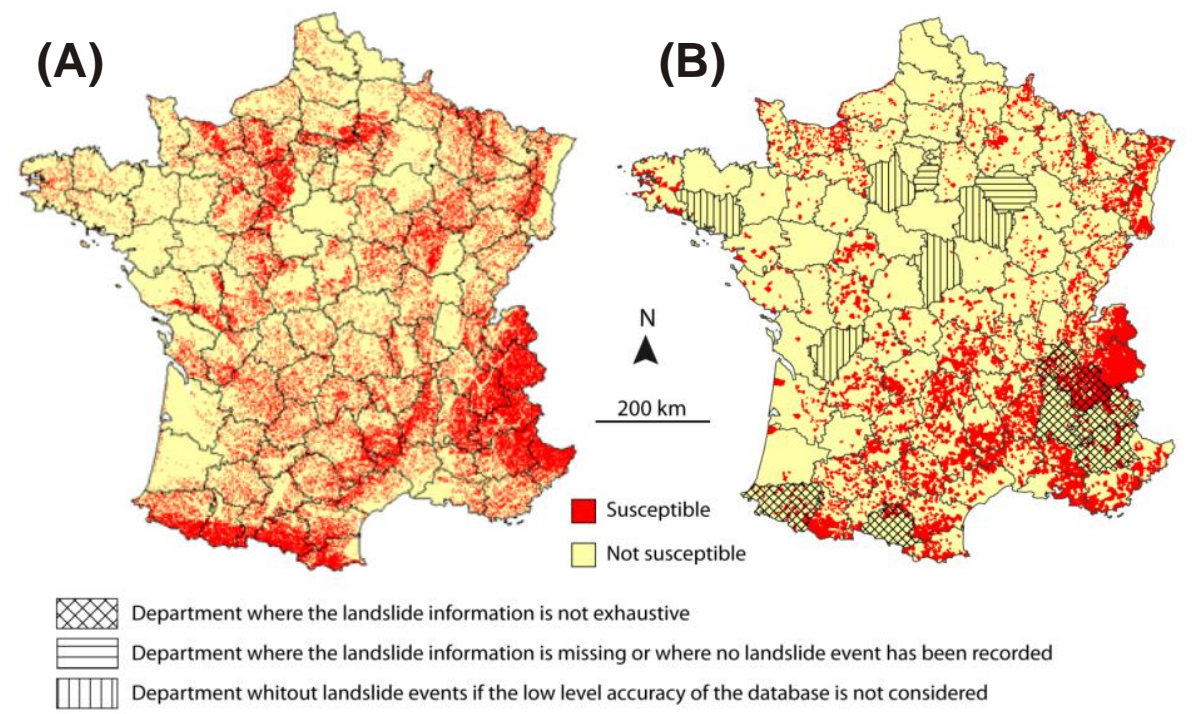

Figure 8 
(A)

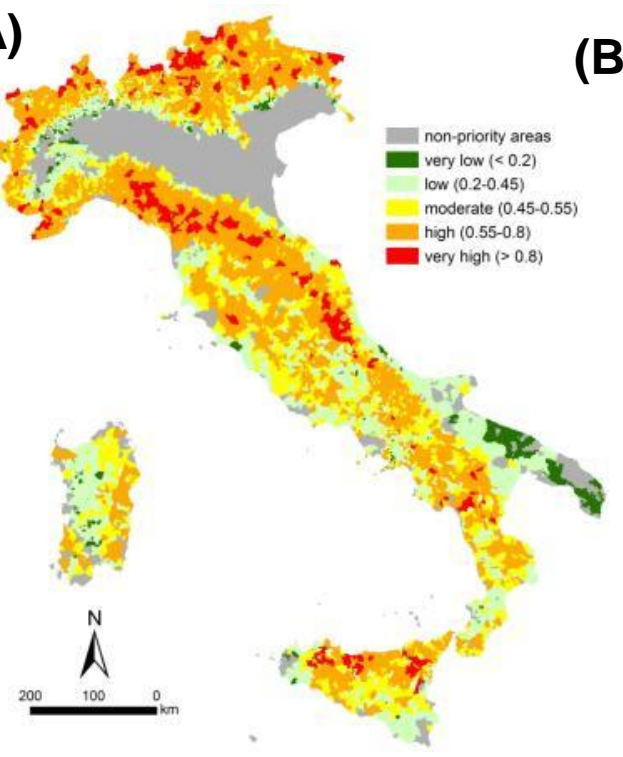

(B)

\begin{tabular}{|cc|c|c|c|}
\hline \multirow{2}{*}{} & \multicolumn{2}{|c|}{ Predicted group (model) } & \multirow{2}{*}{ Total } \\
\cline { 3 - 4 } & $\begin{array}{c}\text { Without } \\
\text { events }\end{array}$ & $\begin{array}{c}\text { With } \\
\text { events }\end{array}$ & \\
\hline \multirow{2}{*}{ Count } & Without events & 2272 & 1280 & 3552 \\
& With events & 881 & 1727 & 2608 \\
\hline \multirow{2}{*}{$\%$} & Without events & 64,0 & 36,0 & 100,0 \\
& With events & 33,8 & 66,2 & 100,0 \\
\hline
\end{tabular}

(C)

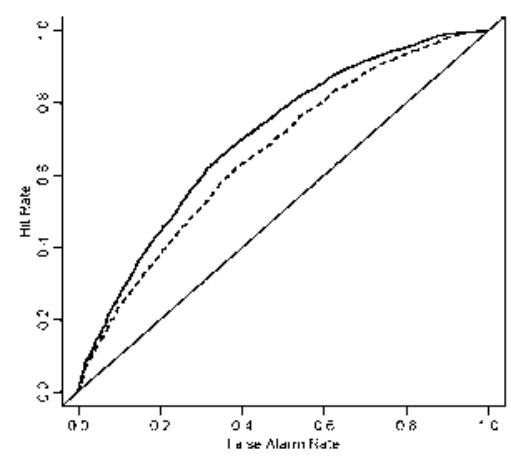

Figure 9 